

\title{
ACCEPTANCE TEST PROCEDURE FOR NEW PUMPING INSTRUMENTATION AND CONTROL SKID "U"
}

\author{
M. R. KOCH \\ CH2MHILL HANFORD GROUP, INC \\ Richland, WA 99352 \\ U.S. Department of Energy Contract DE-AC06-99RL14047
EDT/ECN: 629947 UC:
Cost Center: 74D00 Charge Code: 103361 \\ B\&R Code: EW3120071 Total Pages: 61
}

Key Words: PICS, SALT WELL, SKID, INTERIM STABILIZATION, ACCEPTANCE TEST

\begin{abstract}
:
This Acceptance Test procedure (ATP) provides for the inspection and testing of the new Pumping Insstrumentation and Control (PIC) skid designed as "U". The ATP will be performed after the construction of the PIC skid in the fabrication shop.
\end{abstract}

TRADEMARK DISCLAIMER. Reference herein to any specific commercial product, process, or service by trade name, trademark, manufacturer, or otherwise, does not necessarily constitute or imply its endorsement, recommendation, or favoring by the United States Government or any agency thereof or its contractors or subcontractors.

Printed in the United States of America. To obtain copies of this document, contact: Document Control Services, P.O. Box 950, Mailstop H6-08, Richland WA 99352, Phone (509) 372-2420; Fax (509) 376-4989.
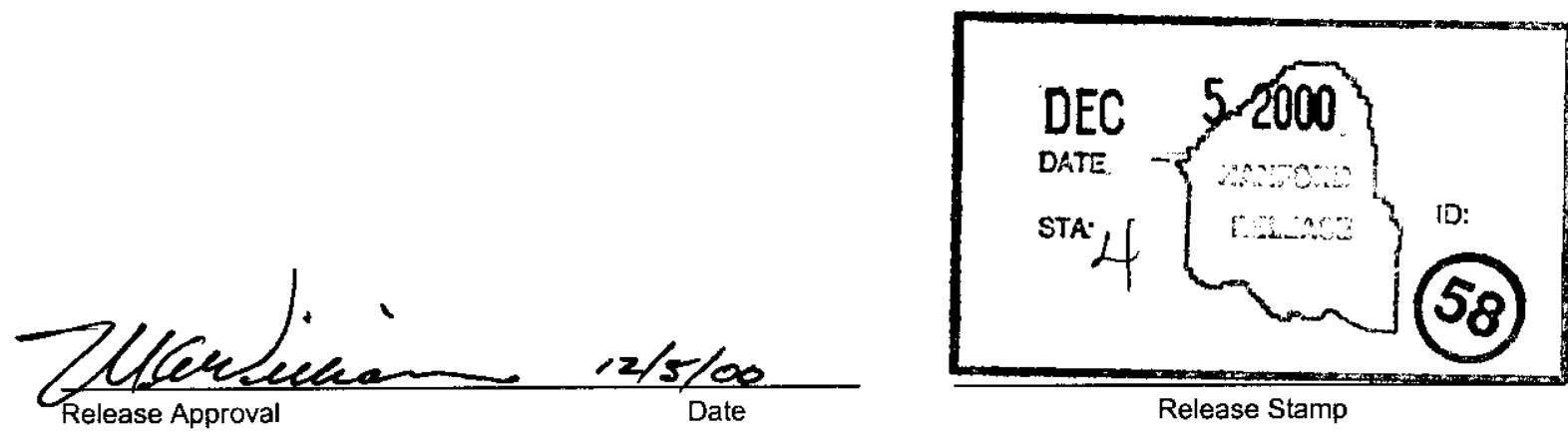


\section{TABLE OF CONTENTS}

\begin{tabular}{|c|c|}
\hline $\mathbf{0}$ & PURPOSE \\
\hline & INFORMATION \\
\hline 2.1 & \\
\hline 2.2 & TERMS AND D \\
\hline 2.3 & RESPONSIBIL \\
\hline 2.4 & SAFETY \\
\hline 2.5 & QUALITY \\
\hline 2.6 & GENERAL INFOR \\
\hline 2.7 & 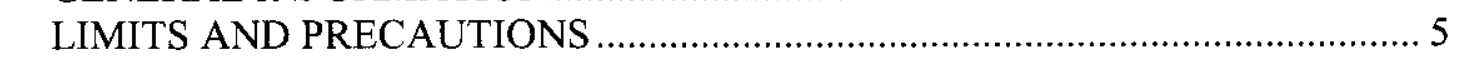 \\
\hline 0 & RECORDS \\
\hline 3.1 & RECORD COPY..... \\
\hline 3.2 & TEST RESL \\
\hline 3.3 & SOFTWARE \\
\hline 0 & 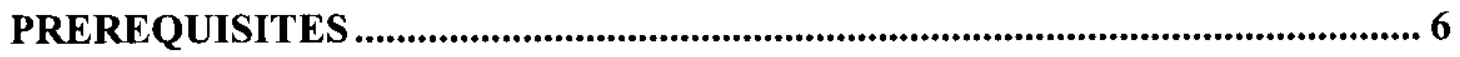 \\
\hline 4.1 & DRAWING VERIFIC \\
\hline 4.2 & REDLINE IN \\
\hline 4.3 & PRESSURE VESSEL INSPECTION................... \\
\hline 4.4 & NATIONAL ELECTRICAL CODE (NEC) INSPECTION ............................. \\
\hline 4.5 & SUPPLIES............. \\
\hline 4.6 & PRESTART C \\
\hline 0 & PROCEDURE ............ \\
\hline 5.1 & CONTINUITY CHECKS ..... \\
\hline 5.2 & MEGGERINC \\
\hline 5.3 & ELECTRICA \\
\hline 5.4 & (1) \\
\hline 5.5 & ICAL AND PROCESS AIR POWER-UP .................................. 20 \\
\hline 5.6 & SKID WAT \\
\hline 5.7 & I T TUE DI $C$ AND DTAM \\
\hline 5.8 & JET PUMP \\
\hline 5.9 & HEATERS, AIR CONDITIONER AND LIGHTS .... \\
\hline & SKID PREPARATION FOR SHIPPING \\
\hline & 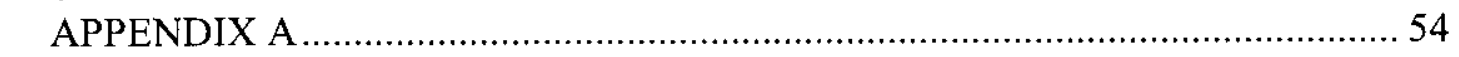 \\
\hline
\end{tabular}




\section{ACCEPTANCE TEST PROCEDURE FOR NEW PUMPING INSTRUMENTATION AND CONTROL SKID "U”}

\subsection{PURPOSE}

This Acceptance Test Procedure (ATP) verifies proper construction per the design drawings and tests for proper functioning of the Pumping Instrumentation and Control (PIC) skid " $U$ ". The scope section lists the systems and functions to be checked. This ATP will be performed at the Site Fabrication Services (SFS) shop upon completion of PIC skid construction.

\subsection{INFORMATION}

\section{$2.1 \quad$ SCOPE}

This Acceptance Test Procedure verifies and/or tests the following items or systems:

2.1.1 Drawing verification (Prerequisites)

2.1.2 Red-line incorporation

2.1.3 Code Inspections (Prerequisites)

2.1.4 Instrument calibrations

2.1.5 Continuity, megger and voltage checks

2.1.6 Programmable Logic Controller (PLC) and Data Table Access Module (DTAM) programming

2.1.7 Air system

2.1.8 Water system

2.1.9 PLC inputs and outputs

2.1.10 Alarms and interlocks

2.1.11 Heaters, air conditioner and lights 


\title{
2.2 TERMS AND DEFINITIONS
}

\author{
2.2.1 DOV - Diaphragm Operated Valve \\ 2.2.2 GPM - Gallons Per Minute \\ 2.2.3 IA - Instrument Air \\ 2.2.4 LDE - Leak Detector Element \\ 2.2.5 PRV - Pressure Relief Valve \\ 2.2.6 SGT - Specific Gravity Transmitter \\ 2.2.7 WFT - Weight Factor Transmitter \\ 2.2.8 LT - Level Transmitter \\ 2.2.9 WFIE - Weight Factor Instrument Enclosure \\ 2.2.10 PLC - Programmable Logic Controller \\ 2.2.11 DTAM - Data Table Access Module \\ 2.2.12 PSPT - Pump Suction Pressure Transducer \\ 2.2.13 PDPT - Pump Discharge Pressure Transducer \\ 2.2.14 PXPT - Pump Transfer Pressure Transducer \\ 2.2.15 JFPT - Jumper Flush Pressure Transducer \\ 2.2.16 ATP - Acceptance Test Procedure \\ 2.2.17 PIC - Person In Charge
}

\subsection{RESPONSIBILITIES}

2.3.1 CHG Quality Assurance is responsible for:

2.3.1.1 Witnessing and signing steps as identified in the Acceptance Test Procedure.

2.3.1.2 Verifying that the ATP sections were performed correctly.

2.3.1.3 Approving Exception resolution and exception closure.

2.3.1.4 Verifying instrument calibration completion.

2.3.1.5 Ensuring drawings verification completion.

2.3.1.6 Acceptance of completed ATP.

2.3.2 Test Engineer (or representative) and/or PIC are responsible for:

2.3.2.1 Identifying the equipment required for the ATP.

2.3.2.2 Recording equipment status and data per this ATP.

2.3.2.3 Conducting pre-job system walk-down.

2.3.2.4 Recording data and other notes during the ATP performance.

2.3.2.5 Providing technical support during the ATP.

2.3.2.6 Providing PLC/DTAM programming support during the ATP.

2.3.2.7 Acting as Test Director during the ATP.

2.3.2.8 Approving Exception resolution and exception closure. 


\section{RPP-6707}

REVISION 0

\section{$2.4 \quad$ SAFETY}

Warning: 120vac energized circuits and leads may be encountered during testing when accessing PLC input/output terminals. Observe appropriate electrical precautions as directed by RPP-PRO-088, Electrical Work Safety.

Warning: Cabinets on the PIC skid contain circuits energized with 480vac and 120vac. Comply with RPP-PRO-088, Electrical Work Safety.

\subsection{QUALITY ASSURANCE}

CHG Quality Assurance Inspector is to ensure that testing is performed per this ATP document. The Quality Assurance Inspector shall sign and date each of the 5.0 sections verifying the data obtained and that the section was performed correctly.

\subsection{GENERAL INFORMATION}

2.6.1 All data entries recorded in this procedure shall be made in black or blue ink.

2.6.2 Editorial changes required to this ATP shall be made by redlining the affected section by the engineer as long as the changes do not impact the personnel safety or the technical aspects of this ATP. These changes shall be recorded on the ATP log sheet.

2.6.3 Unexpected results during testing shall be logged in the Acceptance Test Procedure "Exception Log" and documented on an Acceptance Test Procedure "Exception Record."

2.6.4 Technical changes to this ATP shall be logged as "Exceptions and documented on the "Exception Record."

2.6.5 Do not perform any part of this ATP on faulty equipment. If faulty equipment is discovered, STOP the execution of that section of the ATP and resolve the problem OR continue with another section until the problem is repaired.

2.6.6 Failed equipment or components shall be evaluated for documentation on a Nonconformance Report (NCR).

2.6.7 If the performance of the ATP is suspended for any reason, ensure the equipment is left in a safe condition per the direction of the test engineer and/or PIC and any Lock and Tag system requirements are met before leaving the test site.

2.6.8 This ATP DOES NOT contain separate data/verification sheets. Verification of the ATP steps and validity of data is recorded in this ATP next to each step as required.

2.6.9 A Job Hazard Analysis for shall be used in conjunction with the Pre-job safety meeting form when any unusual hazards are identified. The Pre-job meeting form (attached to this ATP) shall be used to document all attendees. NOTE: No unusual hazards are expected during the performance of this ATP. 


\section{RPP-6707 \\ REVISION 0}

2.6.10 An ATP log shall be used to record comments concerning the ATP performance such as each day's testing activities.

2.6.11 The engineer or PIC may deviate from test steps if necessary to ensure safe equipment configuration during testing or suspension of testing. Configuration shall be noted so the equipment may be restored at the resumption of testing.

2.6.12 Alarms may be acknowledged during testing at the direction of the test engineer or PIC if specific instructions are not given in the test steps.

2.6.13 Sections 4.2, 4.3, 4.4, and 5.4 can be performed out of sequence in order to facilitate the completion of this ATP.

2.6.14 Sections 5.7 through 5.9 can be performed out of order as directed by the test engineer and/or PIC as necessary to facilitate ATP performance.

2.6.15 All personnel performing, initialing and/or signing this ATP shall enter their signature and initials on the Procedure Performer Signature Sheet on the last page of this document.

\subsection{LIMITS AND PRECAUTIONS}

See section 2.4, Safety.

\subsection{RECORDS}

\subsection{RECORD COPY}

The record copy of this ATP when completed shall be kept with the fabrication work package.

\subsection{TEST RESULTS}

A test report, RPP-6708 shall be issued with the final test results upon completion of this ATP.

\subsection{SOFTWARE DOCUMENTATION}

Final software programs shall be documented as required by HNF-5034. This documentation is not part of this ATP, but will be documented in a software report after performance of the OTP in the field. 


\section{REVISION 0}

\subsection{PREREQUISITES}

\subsection{DRAWING VERIFICATION}

A check of the constructed skid is to be compared to either the redlined drawings or the final unreleased skid drawings. Engineering shall verify the accuracy of the essential and support drawings. Engineering shall determine a resolution for all discrepancies by either correcting the drawings or changing the equipment.

The following drawings shall be walked down for verification of proper construction of the skid:

4.1.1 Wire terminations and wiring labels on drawings H-14-104187, sheets 7 through 12 and $\mathrm{H}-14-104190$, sheet 5.

4.1.2 Panel board arrangement on drawing H-14-104193.

4.1.3 Flow diagram on drawing H-14-104192.

Drawing verification completed. (Final drawing release is not required to continue with this ATP.)

Engineer Signature Date

Quality Assurance Inspector Signature Date

\subsection{REDLINE INCORPORATION}

4.2.1 Ensure the redlines identified on the construction drawings in the fabrication work package are incorporated on the final drawings for skid " $U$ " prior to the drawings being released. NOTE: Redlines must meet the intent of the markups and may not be exactly the same in order to meet drafting standards or for clarity.

4.2.2 Engineer to verify the redline incorporation is completed by signing below.

Engineer Signature Date

Quality Assurance Inspector Signature Date




\subsection{PRESSURE VESSEL INSPECTION}

A pressure vessel inspection by a third party inspector is required for the air compressor receiver tank and relief valves located in the air compressor cabinet and the water tank and relief valves located in the water cabinet. The inspection is to verify that the equipment meets National Codes for pressure vessels. An outside-certified inspector shall perform this inspection. (This inspection shall be completed prior to testing the air compressor and water systems.)

Pressure vessel inspection report received. (The ATP can continue before the report is received, but must be received prior to performing sections 5.6 and 5.7.)

Report \#'s: (Inspection \#'s on tanks)

\section{Engineer Signature Date}

Information has, been supplied to the PMS database to add relief valve inspection for the air compressor and water tanks. Completion of the database update will be tracked by the Acceptance for Beneficial Use documentation.

Engineer Signature Date

\subsection{NATIONAL ELECTRICAL CODE (NEC) INSPECTION}

4.4.1 An NEC inspection shall be performed to verify compliance to NFPA 70, latest version.

4.4.2 Areas in particular to be inspected are the 480vac and $120 \mathrm{vac}$ wiring and grounding.

4.4.3 An NEC inspection sticker is to be placed on the inside or the outside of the panel board door upon the NEC inspector's acceptance of the electrical portion of the skid.

The NEC inspection sticker is placed on the panel board door. (This needs to be completed prior to the section 5.0 functional checks.) Report \# (from sticker)

Engineer Signature Date


RPP-6707

REVISION 0

\subsection{SUPPLIES}

The following supplies are required for this ATP.

NOTE: Test sections may commence prior to assembly of all the test equipment. Engineer and/or PIC are to ensure test equipment is available prior to the start of each section.

4.5.1 Volt/ohm meter (VOM): Portable, 0-600vac

Calibration No. Exp. Date QA

Calibration No. Exp. Date QA

Calibration No. Exp. Date QA

4.5.2 Transmation current (milliamp) simulator or equivalent Calibration No. Exp. Date QA

Calibration No. Exp. Date QA

Calibration No. Exp. Date QA

Calibration No. Exp. Date QA

Calibration No. Exp. Date QA

4.5.3 Manometer capable of a minimum of 5 inches water gauge to a maximum of 125 inches water gauge for this ATP and a read-out of variable test pressure.

Calibration No. Exp. Date QA

Calibration No. Exp. Date QA

Calibration No. Exp. Date QA

\subsubsection{Megaohm meter, with a 500vac range.}

Calibration No. Exp. Date QA

4.5.5 Temperature simulator capable of 100 to 150 degrees $F$.

Calibration No. Exp. Date QA Calibration No. Exp. Date QA 
4.5.6 Temperature simulator for RTD with a temperature range of 350 to 400 degrees $\mathrm{F}$.

Calibration No. Exp. Date QA

4.5.7 Stopwatch for timing minutes of flow time.

Calibration No. Exp. Date QA

4.5.8_480vac, 3 phase, 30-ampere power supply for PIC skid.

4.5.9_ Selector switches (3 each) with at least one contact.

4.5.10_ Proximity switches (for simulating LS-1 and LS-2), 2 each.

4.5.11_Leak detector probes ( 2 each) not required to be green tagged.

4.5 .12 Heat gun to warm thermocouple probes.

pump and jumper.

4.5.14_Buckets or pans for water for leak detector test and catching water from DIP tubes and relief valves.

4.5.15_Water supply and hose to fill water tank.

4.5.16 Ice water or cold air spray to cool thermocouple probes.

4.5.17 $—$ Injection pump simulator box. (See Appendix A) 


\subsection{PRESTART CONDITIONS}

4.6.1___ Fill the water tank at least one-third to half full of water. Operate the appropriate valves in the water cabinet to accomplish this task.

4.6.2_ Ensure the PIC skid is grounded in preparation for ATP testing.

4.6.3 Ensure PLC and DTAM programs are loaded into the PLC and DTAM by Engineering.

4.6.4 Ensure the following PIC skid valves in the WFIE cabinet are OPEN prior to starting this ATP.

NOTE: All valves, electrical equipment and instruments are prefixed with "SALW".

V-6035U (EQUALIZING)

V-6036U (EQUALIZING)

4.6.5 Ensure the following valves are CLOSED prior to starting this ATP.

Air Compressor Cabinet

\begin{tabular}{r} 
V-6025U \\
V-6026U \\
V-6034U \\
V-6043U \\
V-6044U \\
V-6046U \\
V-6047U \\
\hline $\mathrm{V}-6048 \mathrm{U}$ \\
$\mathrm{V}-6049 \mathrm{U}$ \\
$\mathrm{V}-6050 \mathrm{U}$ \\
$\mathrm{V}-6051 \mathrm{U}$ \\
$\mathrm{V}-6053 \mathrm{U}$
\end{tabular}

WFIE Cabinet

\begin{tabular}{rr}
$V-6001 \mathrm{U}$ & $\mathrm{V}-6013 \mathrm{U}$ \\
$\mathrm{V}-6002 \mathrm{U}$ & $\mathrm{V}-6014 \mathrm{U}$ \\
$\mathrm{V}-6003 \mathrm{U}$ & $\mathrm{V}-6015 \mathrm{U}$ \\
$\mathrm{V}-6004 \mathrm{U}$ & $\mathrm{V}-6016 \mathrm{U}$ \\
$\mathrm{V}-6005 \mathrm{U}$ & $\mathrm{V}-6017 \mathrm{U}$ \\
$\mathrm{V}-6006 \mathrm{U}$ & $\mathrm{V}-6018 \mathrm{U}$ \\
$\mathrm{V}-6007 \mathrm{~V}$ & $\mathrm{~V}-6019 \mathrm{U}$ \\
\hline $\mathrm{V}-6008 \mathrm{U}$ & $\mathrm{V}-6020 \mathrm{U}$ \\
\hline $\mathrm{V}-6011 \mathrm{U}$ & $\mathrm{V}-6021 \mathrm{U}$ \\
\hline $\mathrm{V}-6012 \mathrm{U}$ &
\end{tabular}

Water Cabinet $\mathrm{V}-6027 \mathrm{U}$ $\mathrm{V}-6029 \mathrm{U}$ $\mathrm{V}-6030 \mathrm{U}$ $\mathrm{V}-6031 \mathrm{U}$ $\mathrm{V}-6032 \mathrm{U}$ $\mathrm{V}-6037 \mathrm{U}$ V-6052U V-6054U V-6055U 


\section{REVISION 0}

4.6.6_Ensure the following PIC skid circuit disconnects, breakers and fuses are OPEN or OFF prior to starting this ATP.

DS-6002U

DS-6003U

DS-6004U

DS-6005U

(The following breakers are located in distribution panel DP-6001U.)

\begin{tabular}{c} 
Breaker "MAIN" \\
\hline Breaker 1 \\
Breaker 3 \\
Breaker 5 \\
Breaker 7 \\
Breaker 9 \\
\hline Breaker 11 \\
\hline Breaker 13
\end{tabular}

Breaker 2

Breaker 4

Breaker 6

Breaker 8

Breaker 10

Breaker 12

Breaker 14

(The following fuses are located in the Instrument Enclosure.)

$\begin{array}{rrr}\text { FA } & \text { FB } & \text { FC } \\ \text { FD } & \text { LD }\end{array}$

4.6.7 Check for loose electrical connections at the following locations:

Terminal boards in the Instrument Enclosure.

Motor starters and disconnect switches.

Terminal board in junction box inside the WFIE cabinet.

Terminal board in heat trace splice box outside WFIE cabinet.

Terminal board in junction box for FGM outside WFIE cabinet.

Distribution panel board.

4.6.8_Ensure desiccant and filters are installed in the air compressor dryer and filters prior to performing sections 5.6 and 5.7.

4.6.9 Ensure check valves in the air compressor and water cabinet are installed in the proper direction. Reference H-14-104192, sheets 1 and 2.

4.6.10 A pre-job safety meeting shall be held prior to performing section 5.0. Attendees shall sign the Pre-job Brief Signature and Performer Signature pages at the back of this document. 


\subsection{PROCEDURE}

\subsection{CONTINUITY CHECKS}

Continuity checks shall be performed with a calibrated VOM. Perform the checks as identified below. Readings are to be less than $1 \mathrm{ohm}$. Record ohm readings on the line(s) provided. Out of tolerance readings must be corrected and rechecked prior to going to the next section. NOTE: NEC inspection must be completed prior to proceeding with this section.

NOTE: All valves, electrical equipment and instruments labels are prefixed with "SALW".

5.1.1 480vac main power plug to the line side of the main disconnect switch (DS$6002 \mathrm{U})$. Check all three phases and ground.
(RED)
(YELLOW)
(BLUE)
(GND)

5.1.2 Load side of main disconnect switch (DS-6002U) to the line side of transformer disconnect switch (DS-6003U). Check the two phases used and ground.

(RED) _ (YELLOW OR BLUE) _ (GND)

5.1.3 Load side of main disconnect switch (DS-6002U) to the line side of the jet pump motor starter (DS-6005U). Check all three phases and ground.
(RED)
(YELLOW)
(BLUE)
(GND)

5.1.4 Load side of main disconnect switch (DS-6002U) to the line side of the air compressor motor starter (DS-6004U). Check all three phases and ground.
(RED)
(YELLOW)
(BLUE) (GND)

5.1.5 Load side of the transformer disconnect switch (DS-6003U) through the primary of the transformer (XFMR-6001U). Check between the two phase wires going to the transformer.

Continuity through the transformer primary. 
RPP-6707

REVISION 0

5.1.6 Line side of the main breaker in panel board (DP-6001U) through the secondary of transformer (XFMR-6001U). Check between the two phases and between each phase and neutral going to the transformer secondary.

Phase A to phase $\mathrm{C}$, continuity through transformer secondary.

Phase A to neutral, continuity through transformer secondary.

Phase $\mathrm{C}$ to neutral, continuity through transformer secondary.

5.1.7 Load side of breakers in distribution panel (DP-6001U) to terminal point identified.

Circuit 3 to TB10 in Instrument Enclosure (CKT3H)

Circuit 5 to TB13 in Instrument Enclosure (CKT5H)

Circuit 2 to TB10 in the Instrument Enclosure (CKT2H)

Circuit 12 to Air Conditioner/Heater receptacle in Instrument Enclosure

Circuit 6 to safe side terminal block in Intrinsic Safe pane]

Circuit 1 to terminal block in FGM power junction box

Circuit 11 to terminal block in FGM power junction box

Circuit 13 to flood light receptacle

Circuit 14 to flood light receptacle

Circuit 10 to terminal block in FGM heat trace splice box

Circuit 4 to receptacle in air compressor cabinet

Circuit 7 to receptacles in WFIE cabinet

Circuit 8 to receptacle in water cabinet

Circuit 9 to outside receptacle below panel board

5.1.8 Section 5.1 completed and all recorded readings within tolerance.

Quality Assurance Inspector Signature

Date 


\subsection{MEGGERING OF POWER WIRES}

The power wires shall be checked for resistance to ground and phase to phase. A 500-volt megger shall be used for this check. Minimum acceptable readings are greater than 1000 megaohm or infinity. Test the circuits listed below. Record readings on the lines provided. Out of tolerance readings must be corrected and rechecked prior to going to the next section.

5.2.1 Each of the three phases at the pins of the power plug to ground and phase to phase. (Ensure main disconnect DS-6002U is OPEN.)
A-GND
; B-GND
; C-GND
; A-B
; A-C

$\mathrm{B}-\mathrm{C}$

5.2.2 Each of the three phases at the load side of the main disconnect switch (DS$6002 \mathrm{U}$ ) to ground and phase to phase. (Ensure switches DS-6003U, DS6004U and DS-6005U are OPEN.)
A-GND
; B-GND
; C-GND
; A-B
; A-C

$\mathrm{B}-\mathrm{C}$

5.2.3 Each of the two phases on the load side of the transformer disconnect switch (DS-6003U) to ground.

A-GND ; B-GND

5.2.4 Each of the three phases on the load side of the air compressor motor to ground.

A-GND ; B-GND ; C-GND

5.2 .5 Disconnect the neutral at the distribution panel from ground.

5.2.6 Each of the two phases and neutral to ground at the distribution panel.

A-GND ; B-GND ; NEUTRAL-GND

5.2 .7 Reconnect the neutral back to ground at the distribution panel.

5.2.8_Disconnect the circuit 6 wire at the safe side terminal block in the Intrinsic Safe panel.

5.2.9_ Disconnect the circuit 5 wire at TB13 for the Instrument Enclosure light. 


\section{RPP-6707 \\ REVISION 0}

5.2.10_Ensure all the heaters, lights and air conditioner are disconnected or unplugged from the $120 \mathrm{vac}$ circuits. Ensure the fan thermostat switch in the air compressor cabinet is set high enough for the switch contacts to be open.

5.2.11 Megger each of the 14 circuits from the load side of the breaker or from the wire disconnected at the load side of the breaker to ground in the distribution panel.

NOTE: Disconnect each wire from the load side of the breaker on all the ground fault breakers prior to performing the megger check. This will prevent damage to the ground fault circuitry in the breaker. Reconnect the wire after meggering.

CKT \#1 to GND
CKT \#3 to GND
CKT \#5 to GND
CKT \#7 to GND
CKT \#9 to GND
CKT \#11 to GND
CKT \#13 to GND

CKT \#2 to GND
CKT \#4 to GND
CKT \#6 to GND
CKT \#8 to GND
CKT \#10 to GND
CKT \#12 to GND
CKT \#14 to GND

5.2.12_Ensure the load-side wire at each breaker where disconnected is reconnected.

5.2.13_Reconnect the circuit 6 wire to the safe side terminal block in the Intrinsic safe panel.

5.2.14___ Reconnect the circuit 5 wire at TB13 for the Instrument Enclosure light.

5.2.15 Section 5.2 completed and all recorded readings are within tolerance.

Quality Assurance Inspector Signature

Date 


\subsection{ELECTRICAL POWER CHECKS}

The voltage checks are to verify proper voltages throughout the skid at specific termination points. Voltages checked are $480 \mathrm{vac}, 3$ phase; $120 \mathrm{vac}$, single phase; $24 \mathrm{vdc}$; and $32 \mathrm{vdc}$. Out of tolerance readings must be corrected when found before going to the next step in this section.

5.3.1___Ensure that all electrical connections are completed. Wires lifted during meggering checks are to be reconnected.

5.3.2_Ensure all switches and breakers are open and the six fuses in the Instrument Enclosure are open.

5.3.3_Ensure all the fuses are installed in the two safety switches (DS-6002U and DS-6003U) and motor starters (DS-6004U and DS-6005U) including the control transformer fuses.

5.3.4 Connect the main power plug on the skid to a three phase, $480 \mathrm{vac}$ power source. Source is to be protected by no greater than a 30 ampere over current protection device.

5.3.5___ Turn ON the power source to the skid.

5.3.6 Ensure 480vac +/-20vac on the line side of the main disconnect switch (DS-6002U). Record the voltage readings.

vac, A-B

$\longrightarrow$ A-C

$\mathrm{B}-\mathrm{C}$

5.3 .7

5.3 .8

Close the main disconnect switch (DS-6002U).

Ensure $480 \mathrm{vac}+/-20 \mathrm{vac}$ on the line side of the transformer disconnect switch (DS-6003U). Record the voltage readings.

vac

5.3.9_Ensure 480vac $+/-20 \mathrm{vac}$ on the line side of the air compressor motor starter (DS-6004U). Record the voltage readings.

vac, A-B

vac, A-C

B-C

5.3.10_Ensure $480 \mathrm{vac}+/ 20 \mathrm{vac}$ on the line side of the pump motor starter (DS$\overline{6005 U})$. Record the voltage readings.

vac, A-B

vac, A-C

B-C 


\section{RPP-6707 \\ REVISION 0}

5.3.11___ Ensure the dead front on the panel board (DP-6001U) is removed for access to the main breaker for a voltage measurement.

5.3.12_Close the transformer disconnect switch (DS-6003U).

5.3.13 Check for 240vac $+/ 20 \mathrm{vac}$ on the line side of the main breaker. Record the voltage reading.

vac

5.3.14____ Open the transformer disconnect switch (DS-6003U).

5.3.15__ Replace the dead front on the panel board (DP-6001U).

5.3.16___ Close the transformer disconnect switch (DS-6003U).

5.3.17_C Close the 100 ampere main breaker in the panel board (DP-6001U).

5.3.18_Check the voltages for the circuits at the locations designated. Record the voltages in the space provided.

\begin{tabular}{|c|l|c|c|c|}
\hline CKT \# & \multicolumn{1}{|c|}{ Check voltage at } & $\begin{array}{c}\text { Bkr Open voltage } \\
\text { (appr. 0vac) }\end{array}$ & $\begin{array}{c}\text { Bkr Closed voltage } \\
(120+/-10 \mathrm{vac})\end{array}$ & $\begin{array}{c}\text { Open } \\
\mathrm{Bkr}\end{array}$ \\
\hline 1 & FGM JUNCTION BOX & & & \\
\hline 2 & TB10, INSTR ENCL & & & \\
\hline 3 & TB10, INSTR ENCL & & & \\
\hline 4 & RCPT, AIR COMPR & & & \\
\hline 5 & TB13, INSTR ENCL & & & \\
\hline 6 & TB, INTRINSIC PNL & & & \\
\hline 7 & RCPT, WFIE CAB. & & & \\
\hline 8 & RCPT, WATER CAB. & & & \\
\hline 9 & OUTSIDE RCPT & & & \\
\hline 10 & FGM HT BOX & & & \\
\hline 11 & FGM JUNCTION BOX & & & \\
\hline 12 & RCPT, INSTR ENCL & & & \\
\hline 13 & RCPT, FLOOD LIGHT & & & \\
\hline 14 & RCPT, FLOOD LIGHT & & & \\
\hline
\end{tabular}


5.3.19 ENSURE fuses FA, FB, FC, FD, LD, and HT are installed in the fuseholders and the fuse switches are CLOSED in the Instrument Enclosure.

5.3.20_Close breakers 2, 3 and 5 in the distribution panel (DP-6001U).

5.3.21_Ensure 120vac $+/-10 \mathrm{vac}$ on the load side at the following fuseholders.

FA vac; FB vac; $\mathrm{FC}$ vac;

FD vac;

(LD) vac; (HT) vac. Ensure $24 \mathrm{vdc}+/-2 \mathrm{vdc}$ at the 24 volt power supply. vdc. Close breaker 6 in the distribution panel (DP-6001U).

5.3.24_Ensure $32 \mathrm{vdc}+3 /-4 \mathrm{vdc}$ at the output of the 3991 power supply in the Intrinsic safe panel (terminals 3 and 4). NOTE: Low voltage reading may indicate the $240 / 120 \mathrm{vac}$ input power switch on the side of the 3991 supply is in the wrong position.) VDC

5.3.25_Open breakers 2, 3, 5, and 6 in the panel board (DP-6001U).

5.3.26_Open the 100 ampere main breaker in the panel board (DP-6001U).

5.3.27_Open the transformer disconnect switch (DS-6003U).

5.3.28___ Open the main disconnect switch (DS-6002U).

5.3.29 Voltage checks completed and readings within tolerance. 


\subsection{CALIBRATIONS}

Instrumentation equipment on the skid requires calibration prior to the functional testing. Engineering will verify the calibration completion by checking for current calibration stickers on the equipment and checking off the completed calibrations in the table below.

\begin{tabular}{|l|l|l|}
\hline \multicolumn{1}{|c|}{ INSTRUMENT } & \multicolumn{1}{c|}{ LOCATION } & CAL. STICKER ON \\
\hline SALW-PS-6004U & AIR COMPR. CABINET & \\
\hline SALW-WFT-6002U & WFIE CABINET & \\
\hline SALW-LT-6003U & WATER CABINET & \\
\hline SALW-SGT-6001U & WFIE CABINET & \\
\hline SALW-CONV-6001U & WFIE CABINET & \\
\hline SALW-FQIT-6001U & INSTRUMENT ENCL. & \\
\hline SALW-PI-6006U & AIR COMPR. CABINET & \\
\hline SALW-PI-6007U & AIR COMPR. CABINET & \\
\hline SALW-PI-6008U & WATER CABINET & \\
\hline SALW-PI-6001U & WFIE CABINET & \\
\hline SALW-PI-6002U & WFIE CABINET & \\
\hline SALW-PI-6003U & WFIE CABINET & \\
\hline SALW-PI-6004U & WFIE CABINET & \\
\hline SALW-PI-6005U & WFIE CABINET & \\
\hline SALW-PI-6011U & INSTRUMENT ENCL. & \\
\hline SALW-PI-6012U & INSTRUMENT ENCL. & \\
\hline
\end{tabular}

Work package nos.

Ensure the calibrations are completed and there is a current calibration sticker on each of the above instruments.
Engineer Signature
Date

Quality Assurance Inspector Signature

Date 


\subsection{SKID ELECTRICAL AND PROCESS AIR POWER-UP}

NOTE: The pressure vessel inspection report must be received prior to proceeding with this section. Refer to section 4.3. Ensure desiccant is in the air dryer and the filters installed.

5.5.1_Ensure the skid is connected to the $480 \mathrm{vac}$ power source and grounded before proceeding with this functional test.

5.5.2_Energize or ensure energized the PIC skid by CLOSING the following disconnect switches in the order listed below.

NOTE: Ensure the Air Compressor selector switch on DS-6004U is in the OFF position.

DS-6002U
DS-6003U
DS-6004U
DS-6005U

5.5.3_Energize or ensure energized the breakers in the panel board (DP$\overline{6001 U)}$.

\begin{tabular}{c} 
Breaker "MAIN" \\
\hline Breaker 1 \\
Breaker 3 \\
Breaker 5 \\
Breaker 7 \\
\hline Breaker 9 \\
Breaker 11 \\
\hline Breaker 13
\end{tabular}

Breaker 2 Breaker 4 Breaker 6 Breaker 8 Breaker 10 Breaker 12 Breaker 14

5.5 .4 ACKNOWLEDGE any initial skid alarms.

5.5 .5 OPEN valves V-6034U, V-6050U, and $\mathrm{V}-6053 \mathrm{U}$ in the Air compressor cabinet.

5.5.6 START the air compressor by positioning the positioning the switch on DS-6004U to the ON position.

5.5.7_ Ensure the air compressor starts and builds up pressure and shuts off at 86 to 94 psig as indicated by pressure gauge PI-6006U. RECORD the shut off pressure: psig. 


\section{RPP-6707 \\ REVISION 0}

5.5.8_CHECK the tubing in the air compressor cabinet using a soap and water test to visually identify any air leaks. Repair as necessary. Deenergize the compressor motor and bleed off air as necessary to make repairs.

5.5.9_BLEED off air by slowly opening valve V-6043U until the compressor restarts and note the restart pressure as read on gauge PI-6006U. CLOSE valve V-6043U when the compressor restarts. RECORD the restart pressure reading: psig.

5.5.10___ENSURE the compressor restarts between 58 to $62 \mathrm{psig}$.

5.5.11 Valve in air to the PIC skid water tank by performing the following steps.

5.5.12 Check for air leaks as each of the remaining steps in this section are performed.

5.5.13_ SLOWLY OPEN valve V-6025U located in the air compressor cabinet.

5.5.14___ SLOWLY OPEN valve V-6027U located near the water tank.

5.5.15_SLOWLY OPEN valve V-6052U located near the water tank

5.5.16_ADJUST pressure regulator valve PCV-6006U to 30psi (+/-3psi) as indicated by pressure gauge PI-6008U on the outside of the water cabinet. psi

5.5.17_ ACTUATE the lever on relief valve PRV-6004U on the top of the air compressor tank and hold open approximately 5 seconds. (Air system is to be at full pressure of approximately $90 \mathrm{psi}$.)

5.5.18___ENSURE the relief valve PRV-6004U seats properly when the lever is released.

5.5.19_ACTUATE the lever on relief valve PRV-6005U on the top of the water tank and hold open approximately 5 seconds. (Water system air pressure is to be at full pressure of approximately $30 \mathrm{psi}$.)

5.5.20___ENSURE the relief valve PRV-6005U seats properly when the lever is released.

5.5.21 VALVE IN air to the WFIE cabinet by performing the following steps.

5.5.22_SLOWLY OPEN valves_ V-6051U located inside the air compressor cabinet and _ _ V-6026U located on the outside of the air compressor cabinet. 


\section{RPP-6707 \\ REVISION 0}

5.5.23 SLOWLY OPEN valve V-6001U located in the WFIE cabinet. (NOTE: PRV-6002U may open if pressure through PCV-6001U is too high.)

5.5.24 ADJUST pressure control valve PCV-6001U in the WFIE cabinet to 20psi $(+/-2.5 \mathrm{psi})$ as indicated by the pressure gauge located on the face of the valve.

5.5.25_SLOWLY OPEN valve V-6004U located in the WFIE cabinet.

5.5.26_SLOWLY OPEN valve V-6003U located in the WFIE cabinet.

5.5.27_ SLOWLY OPEN valve V-6005U located in the WFIE cabinet.

5.5.28_ SLOWLY OPEN valve V-6006U located in the WFIE cabinet.

5.5.29_ SLOWLY OPEN valve V-6007U located in the WFIE cabinet.

5.5.30_ SLOWLY OPEN valve V-6020U located in the WFIE cabinet.

5.5.31_ SLOWLY OPEN valve V-6021U located in the WFIE cabinet.

5.5.32_ SLOWLY OPEN valve V-6019U located in the WFIE cabinet.

5.5.33 ADJUST the air flow through the diptubes by performing the following steps.

NOTE: Ensure the DIP tubes are not capped on the outside of the WFIE cabinet when performing steps 5.6.34 through 5.6.36.

5.5.34_ADJUST flow to dip tube to $1.5 \mathrm{CFH}(+/-0.5 \mathrm{CFH})$ as indicated by FIV-6002U.

5.5.35_ADJUST flow to dip tube to $1.5 \mathrm{CFH}(+/-0.5 \mathrm{CFH})$ as indicated by FIV-6003U.

5.5.36_ADJUST flow to dip tube to $1.5 \mathrm{CFH}(+/-0.5 \mathrm{CFH})$ as indicated by FIV-6004U.

5.5.37 ENSURE air flow from pressure regulator PCV-6007U by slowly opening valve $\mathrm{V}-6044 \mathrm{U}$ in the air compressor cabinet and then reclose the valve.

5.5.38__ ENSURE air flow from pressure regulator PCV-6008U by slowly opening valve $\mathrm{V}-6048 \mathrm{U}$ in the air compressor cabinet and then reclose the valve. 


\section{RPP-6707 \\ REVISION 0}

5.5.39__ ENSURE air flow from the V-6042U port at the air compressor cabinet by slowly opening valve $\mathrm{V}-6046 \mathrm{U}$ in the air compressor cabinet and then close the valve.

5.5.40_ENSURE air flow from the drain line by slowly opening valves $\mathrm{V}$ $6047 \mathrm{U}$ and $\mathrm{V}-6046 \mathrm{U}$ in the air compressor cabinet and then close the two valves.

5.5.41 Engineer to ENSURE section 5.5 is completed and sign below.

Engineer Signature Date

5.6.42 Quality Assurance Inspector to VERIFY that section 5.6 is complete and sign below.

Quality Assurance Inspector Signature

Date 


\subsection{SKID WATER DRIP SYSTEM}

5.6.1 _ PROVIDE a container to capture water expelled from the dip tubes and the pressure relief valve PRV-6001U on the outside of the WFIE cabinet.

5.6.2 ACTUATE the Dip Tube Drip system by SLOWLY OPENING the following valves in the WFIE cabinet:

$\begin{array}{r}\mathrm{V}-6016 \mathrm{U} \\ -\mathrm{V}-6013 \mathrm{U} \\ \hline\end{array}$

CAUTION: Relief valve PRV-6001U will actuate and relieve pressure at $25 \mathrm{psig}$. NOTE: Back off regulator PCV-6005U prior to performing step 5.7.3.

\section{6 .3} SLOWLY OPEN V-6018U WHILE CAREFULLY ADJUSTING Pressure Regulator PCV-6005U located in the WFIE cabinet to 20psig (t/$2 \mathrm{psig}$ ) as indicated on gauge PI-6001U in the WFIE cabinet.

5.6.4_ADJUST valve V-6014U to allow approximately 2 drops/second as indicated by sight glass FG-6001U.

5.6.5_ADJUST valve V-6015U to allow approximately 2 drops/second as indicated by sight glass FG-6002U.

5.6.6_ OPEN valve V-6056U very slightly to verify water flow from the "Water Supply to Remote Drip Control" port located on the outside of the WFIE cabinet, then CLOSE valve V-6056U when water is observed.

5.6.7 VALVE OUT the dip tube drip system by SLOWLY CLOSING or ENSURING CLOSED the following valves located in the WFIE cabinet.

$\begin{array}{r}V-6015 U \\ \hline \quad V-6014 U \\ \hline \quad V-6008 U \\ \hline V-6013 U \\ \hline V-6019 U \\ \hline V-6021 U \\ \hline \quad V-6020 U \\ \hline \quad V-60006 U \\ \hline V-6005 U\end{array}$




\section{RPP-6707 \\ REVISION 0}

5.6.8 Engineer to ENSURE section 5.7 is completed and sign below.

Engineer Signature Date

5.6.9 Quality Assurance Inspector to VERIFY that section 5.7 is complete and sign below.

Quality Assurance Inspector Signature Date 
RPP-6707

REVISION 0

\subsection{INPUT SIGNALS TO THE PLC AND DTAM}

\section{WATER TANK LEVEL TRANSMITTER}

5.7 .1 ENSURE valve V-6029U located in the water tank cabinet is CLOSED. ENSURE valve V-6031U located in the water cabinet is CLOSED.

5.7 .3 CONNECT a test manometer pressure source that can output at least 62 " water gauge to the HIGH PRESSURE vent/test port of level transmitter LT-6003U.

5.7 .4 ENSURE the LOW PRESSURE vent/test port of level transmitter LT$6003 \mathrm{U}$ is OPEN to atmosphere.

5.7.5_ADJUST the test manometer connected to LT-6003U to a pressure of 31 "water gauge (+/-1"). Record reading

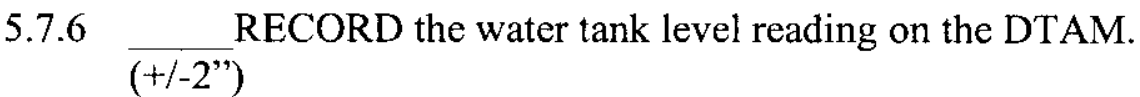
$31 "$

5.7.7 The next step will cause a low water level alarm on the DTAM.

5.7.8_VERY SLOWLY DECREASE the test manometer pressure until the "PIC WATER LEVEL LOW" (alarm 9) occurs on the DTAM. (This alarm should occur at $12.25 "+/-0.5$ " water gauge.)

5.7 .9 ACKNOWLEDGE the alarm at the DTAM. RECORD the manometer pressure and the DTAM water level readings.

Pressure on manometer Water Level on DTAM

5.7 .11 SLOWLY INCREASE the manometer pressure until the alarm clears on the DTAM. (This should occur at 15.5 " $+/-0.5$ " water gauge.) RECORD the manometer pressure and the DTAM water level readings.

Pressure on manometer Water Level on DTAM ENSURE the "PIC Water" alarm indicates "norm".

5.7 .14 REMOVE the test manometer from the LT-6003U high pressure vent/test port and reinstall the vent plugs on both the high and low sides. 
5.7.15___ OPEN valve V-6029U located in the Water Cabinet.

5.7.16___ OPEN valve V-6031U located in the Water Cabinet.

5.7.17___ENSURE "Water Tank" reading on the DTAM shows a value in inches.

Record the reading

\section{WEIGHT FACTOR TEST}

5.7.18_CONNECT a test manometer pressure source that can output at least 125 " water gauge to the HIGH PRESSURE dip tube on the side of the WFIE Cabinet.

5.7.19___ENSURE V-6001U is CLOSED.

5.7.20 ENSURE V-6005U is OPEN.

5.7.21_ENSURE V-6006U is OPEN.

5.7.22_ENSURE adjustment valves on FIV-6002U, FIV-6003W and FIV6004U are CLOSED.

5.7.23 ENSURE the LOW and HIGH side isolation valves located on the V6036U 3-Valve manifold in the WFIE cabinet are OPEN.

5.7.24_ENSURE the EQUALIZING valve located on the V-6036U 3-Valve manifold in the WFIE cabinet is CLOSED.

5.7.25_SET the test manometer to $125^{\prime \prime}(+/-1$ ") water gauge. Record the manometer reading.

5.7.26_ RECORD the "WFT" reading on the DTAM. The reading is to be 125 " $\overline{(+/-5 ")}$.

5.7.27_BLEED off the pressure on the test manometer. Leave connected for testing the specific gravity transmitter.

5.7.28_ OPEN the EQUALIZING valve located on V-6036U 3-Valve manifold in the WFIE cabinet.

5.7.29_CLOSE the LOW and HIGH side isolation valves located on the V6036U 3-Valve manifold in the WFIE cabinet. 


\section{RPP-6707 \\ REVISION 0}

5.7 .30

CLOSE V-6006U.

\section{SPECIFIC GRAVITY TRANSMITTER}

5.7 .31 ENSURE V-6007U is OPEN.

5.7 .32 ENSURE V-6005U is OPEN.

5.7.33 ENSURE the LOW and HIGH side isolation valves located on V6035U 3-Valve manifold in the WFIE cabinet are OPEN.

5.7.34_ENSURE the specific gravity transmitter equalizing valve located on the V-6035U 3-Valve manifold located in the WFIE cabinet is CLOSED.

5.7.35___ SET the test manometer to 5"water gauge (+/- 0.3").

5.7.36 RECORD the "SGT" reading on the DTAM. Reading to be 5" + $0.35^{\prime \prime}$.

5.7.37___BLEE off pressure on the manometer.

5.7.38___ ENSURE "SGT LOW" alarm occurs (alarm 13).

5.7.39___ ACKNOWLEDGE the alarm.

5.7.40____ DISCONNECT the test manometer.

5.7.41_OPEN the EQUALIZING valve located on V-6035U 3-Valve manifold in the WFIE cabinet.

5.7.42 CLOSE the LOW side and HIGH side isolation valves located on V6035U 3-Valve manifold in the WFIE cabinet.

5.7.43_CLOSE V-6005U.

5.7.44_CLOSE V-6007U.

\section{FLOW METER SIGNAL CHECK}

5.7.45 Prepare the flow converter FQIT-6001U located in the Instrument Enclosure to simulate a flow either using the buttons on the front face or using a "brain terminal". 
5.7.46_SIMULATE a flow signal of $50 \%$ span ( 4 or $7 \mathrm{gpm}$ ) with the hand-held brain terminal or from the flow converter face switches. (Set $\mathrm{H} 1$ to 1 and $\mathrm{H} 2$ to 050 .)

5.7.47_RECORD the flow readings on the front of the flow converter and on the DTAM (PMP FLOW). Readings to be within +/- 0.2gpm of each other.

Flow converter DTAM (PMP FLOW)

5.8.48_RESTORE the flow converter, FQIT-6001U to its original configuration. (Set $\mathrm{H} 1$ to 0 . $\mathrm{H} 2$ can be left as 050 .)

\section{SUCTION AND DISCHARGE PRESSURE SIGNAL}

5.7.49_ENSURE a current source is connected to PSPT + and PSPT- on the intrinsic side terminal board in the Intrinsic Safe panel. Set the source to "transmitter simulate."

5.7.50__ SET the current source to approximately $4 \mathrm{~mA}$ and record the suction pressure reading on PI-6012U. Reading to be approximately zero.

psi

5.7.51__ SET the current source to approximately $20 \mathrm{~mA}$ and record the suction pressure reading on PI-6012U. Reading to be approximately $100 \mathrm{psi}$. psi

5.7 .52 DISCONNECT the current source.

5.7.53___ ENSURE a current source is connected to PDPT+ and PDPT- at the intrinsic side terminal board in the Intrinsic Safe panel. Set the source to transmitter simulate.

5.7.54__ SET the current source to approximately $4 \mathrm{~mA}$ and record the discharge pressures on PI-6011U and on the DTAM. Readings should be approximately zero.

PI-6011W psi DTAM (PMP DISC) psi

5.7.55_ SET the current source to approximately $20 \mathrm{~mA}$ and record the discharge pressures on PI-6011U and on the DTAM. Readings should be approximately $300 \mathrm{psi}$.

PI-6011W psi DTAM (PMP DISC) psi 

DISCONNECT the current source.

\section{THERMOCOUPLE INPUTS TO THE PLC}

5.7.57__ WARM thermocouple TE-6004U located in the Instrument Enclosure. change.

ENSURE the "PLC CAB temp" on the DTAM displays a temperature

5.7.59 CONTINUE to warm the thermocouple until "PLC Enclosure HI" (alarm 10 ) occurs. This will be approximately 130 degrees F.

5.7.60 ACKNOWLEDGE the alarm.

5.7.61_ENSURE "PLC CAB temp" on the DTAM shows a temperature DECREASE after the heat source is removed from the TE-6004U thermocouple.

5.7.62_ENSURE the "PLC temp" alarm returns to "norm" when the temperature decreases below 125 degrees $F$.

5.7.63___ WARM thermocouple TE-6001U located in the Air Compressor Cabinet.

5.7.64_ENSURE the "COMPRS temp" on the DTAM displays a temperature change.

5.7.65_CONTINUE to warm the thermocouple until "Air Compressor Temp HI" (alarm 11) occurs. This will be approximately 130 degrees F.

5.7.66_ACKNOWLEDGE the alarm.

5.7.67_ENSURE "COMPRS temp" on the DTAM shows a temperature DECREASE after the heat source is removed from the TE-6001U thermocouple.

5.7.68___ENSURE the "CMPRSR temp" alarm returns to "norm" when the temperature decreases below 125 degrees $\mathrm{F}$.

5.7.69 COOL the thermocouple probe TE-6006U in the WFIE cabinet using ice water or cool air spray. Temperature needs to drop below 35 degrees $F$. ENSURE alarm 50, "WFIE CAB Temp Low" occurs at the DTAM. 


\section{RPP-6707 \\ REVISION 0}

5.7.71 WARM or ALLOW to warm the thermocouple probe TE-6006U in the WFIE cabinet and ENSURE the "WFIE CAB Temp" alarm is "norm" when the temperature goes above 40 degrees $\mathrm{F}$.

5.7.72____COOL the thermocouple probe TE-6005U in the Water cabinet using ice water or cool air spray. Temperature needs to drop below 35 degrees F.

5.7 .73 ENSURE alarm 49, "WATER CAB Temp Low" occurs at the DTAM.

5.7 .74 WARM or ALLOW to warm the thermocouple probe TE-6005U in the Water cabinet and ENSURE the "WATER CAB Temp" alarm is "norm" when the temperature goes above 40 degrees $\mathrm{F}$.

5.7.75 CONNECT a temperature simulator to the intrinsic side of the thermocouple module (MTL 3081) for temperature element TE-6009 in the Intrinsic Safe panel.

5.7.76___ SET the temperature simulator to approximately 120 degrees F.

5.7.77_ENSURE the "F Wtr" temperature reading at the DTAM is approximately 120 degrees $F$. degrees $\mathrm{F}$

5.7.78___ SET the temperature simulator to approximately 180 degrees F.

5.7.79_ENSURE the " $F$ Wtr" temperature reading at the DTAM is approximately 180 degrees $\mathrm{F}$. degrees $\mathrm{F}$

5.7 .80 SET the temperature simulator to approximately 40 degrees $\mathrm{F}$.

5.7.81_ENSURE the "F Wtr" temperature reading at the DTAM is approximately 40 degrees $\mathrm{F}$. degrees $\mathrm{F}$

5.7.82_DISCONNECT the temperature simulator at the Intrinsic Safe panel from the 3081 module for TE-6009.

5.7.83 CONNECT two temperature simulators to the intrinsic side of the two thermocouple modules (MTL 3081) for TE-6003 and TE-6007 in the Intrinsic Safe panel.

5.7 .84 ENSURE the temperature setpoints for the "JumperTemp" and "PumpAssy Temp" are set for 160 degrees F.

5.7 .85 SET both temperature simulators to approximately 120 degrees $\mathrm{F}$. ENSURE the "PMPASY temp" and the "JMPER TEMP" each read approximately 120 degree at the DTAM. (Pump) (Jumper) 

ENSURE the "HEAT TRACE Htr" is ON at the DTAM.

5.7.88_ DECREASE the temperature simulator for TE-6007 to approximately 39 degrees or lower until alarm 8 "Pump/Jumper Temp Trouble" alarms on the DTAM. ACKNOWLEDGE the alarm.

5.7.90_ENSURE the "PMPASY TEMP" reads approximately 39 degree at the DTAM.

5.7.91_INCREASE the temperature simulator for TE-6007 to approximately 120 degrees.

5.7.92_ENSURE the "PMP/JMPR HT" alarm on the DTAM reads "norm".

5.7.93___ENSURE the "Heat Trace Htr" is ON at the DTAM.

5.7.94_ENSURE approximately 120vac between HT-1 and CKT3-N at TB12. vac

5.7.95___ WHILE MONITORING the voltage at TB12, INCREASE the temperature on TE-6003 to 166 degrees F or higher until the voltage at TB12 goes to approximately zero. DTAM temp.

5.7.96_ WHILE MONITORING the voltage at TB12, decrease the temperature on TE- 6003 to 154 degrees F or lower until the voltage at TB12 goes to approximately $120 \mathrm{vac}$. DTAM temp.

5.7.97__ TURN OFF the heat trace from the DTAM.

5.7.98__ ENSURE the voltage at TB12 goes to approximately zero.

5.7.99_ TURN ON the heat trace from the DTAM.

5.7.100___ENSURE the voltage at TB12 returns to approximately $120 \mathrm{vac}$.

5.7.101_ENSURE approximately $120 \mathrm{vac}$ between HT-12 and CKT3-N at TB15. vac

5.7.102___ WHILE MONITORING the voltage at TB15, INCREASE the temperature on TE-6007 to 166 degrees F or higher until the voltage at TB15 goes to approximately zero. DTAM temp. 
5.7.103_WHILE MONITORING the voltage at TB15, decrease the temperature on TE- 6007 to 154 degrees $F$ or lower until the voltage at TB15 goes to approximately $120 \mathrm{vac}$. DTAM temp.

5.7.104_ TURN OFF the heat trace from the DTAM.

5.7.105____ENSURE the voltage at TB15 goes to approximately zero.

5.7.106_ TURN ON the heat trace from the DTAM.

5.7.107___ENSURE the voltage at TB15 returns to approximately $120 \mathrm{vac}$.

5.7.108_R_ REMOVE the temperature simulators from TE-6003 and TE-6007.

5.7.109_CONNECT a temperature simulator to the MTL 5074 module in the Intrinsic Safe panel to simulate an RTD.

5.7.110_ SET the simulator to approximately 360 degrees F.

5.7.11___ENSURE the "MTR WINDING" temperature at the DTAM reads approximately 360 degrees $\mathrm{F}$.

5.7.112_INCREASE the temperature on the simulator to 380 degrees $\mathrm{F}$ or higher until alarm 59, "MOTOR WINDING HI TEMP WARNING" comes in at the DTAM. Acknowledge the alarm. RECORD temperature reading at DTAM and on simulator

5.7.114_ DECREASE the temperature on the simulator to 370 degrees $F$ or lower until the "MTR WNDG TEMP" on the DTAM indicates "NORM."

5.7.115_L_LEAVE the simulator connected for section 5.9, for the checking of the motor winding temperature interlock.

5.7.116_ENSURE a normally closed switch is connected to "BM-1" and "BM2" on the intrinsic safe terminal board in the Intrinsic Safe panel.

5.7.117_ENSURE the "PUMP BEARING" reads "NORM" at the DTAM.

5.7.118___ OPEN the "BM" switch at the Intrinsic Safe panel.

5.7.119_ENSERE alarm 58, "PUMP WORN BEARING ALERT" actuates at the DTAM. Acknowledge the alarm.

5.7.120___ CLOSE the "BM" switch. 
RPP-6707

REVISION 0

5.7 .121 ENSURE the "PUMP BEARING" reads "NORM" at the DTAM.

5.7.122___ DISCONNECT the "BM" switch at the Intrinsic Safe panel.

5.7.123Engineer to Ensure section 5.8 is completed and sign below.

Engineer Signature Date

5.7.124Quality Assurance Inspector to Verify that section 5.8 is complete and sign below.

Quality Assurance Inspector Signature Date 


\subsection{JET PUMP INTERLOCK CIRCUITS}

5.8.1_ ENSURE two proximity switches are connected to the intrinsic safe terminal block in the Intrinsic Safe panel. Connect a proximity switch temporarily labeled as LS-1 to "LS-1(+) and LS-1(-)" and a proximity switch temporarily labeled as LS-2 to "LS-2(+) and LS-2(-)". ACTUATE the proximity switches by placing metal in front the switch faces.

5.8 .2

IF POSSIBLE, CONNECT two current sources to the following points. One to JFPT + and JFPT- at the intrinsic terminal board; and one to PXPT+ and PXPT- at the intrinsic terminal board in the Intrinsic safe panel. Set the current sources to "transmitter simulate" and at 6mA. NOTE: If two current sources are not available, then software forces will be used during this section to bypass the inputs not being tested.

SET the temperature simulator connected to the MTL 5074 module at the Intrinsic Safe panel to 360 degrees F.

5.8.4 ENSURE a normally closed switch is connected to "DIL-F" and "CKT5H-A" on terminal board TB4 in the Instrument Enclosure.

5.8.5_ENSURE a normally closed switch is connected to " $\mathrm{C} 2$ " and " $\mathrm{NC1}$ " on the power monitor in the Jet Pump motor starter. Connect to the "C2" terminal on the power monitor and lift the "NC1" wire and connect to the lifted "NC1" wire.

5.8.6 ENSURE a normally closed switch is connected to "BY105" and "CKT5H-A" on terminal board TB4 in the Instrument Enclosure.

5.8 .7 ENSURE a normally closed switch is connected to "BX-DCRT" and "CKT5H-A" on terminal board TB4 in the Instrument Enclosure.

5.8.8 ENSURE the two leak-detector probes are connected to the skid at the Instrument Enclosure.

ENSURE the injection pump simulator box (See Appendix A) is connected to the following points in the Instrument Enclosure. WARNING: DO NOT plug in the box until the connections are made. Connect wires 1 and $1 \mathrm{~A}$ to points 1 and $1 \mathrm{~A}$ at TB3. Connect wires FWFS- 1 and CKT5H-B to the corresponding points on TB6. After connections are made, connect the box to a 120vac power source.

5.8 .10 ENSURE the DIP switches for the Pepperl-Fuch module in the Intrinsic Safe panel are set to the correct positions: $\mathrm{S} 1$ and S2 in position II; and S3 in position $\mathrm{I}$. 


\section{REVISION 0}

5.8.11_ENSURE the laptop computer is connected to the PLC to set forces and observe logic when required.

5.8.12 RECORD the reading of the Hourmeter on the front of the Instrument Enclosure.

5.8.13_ ENSURE the green light on the Instrument Enclosure and on the Jet $\overline{\text { Pump }}$ motor starter are ON.

5.8 .14 APPLY software forces to allow the jet pump to start. (Engineering will apply the forces from the laptop computer connected to the PLC.

Normally this will be the COMM Failure and any leak station interlocks.

These can be forced out by setting the timers to a high set value such as 7200 seconds with the laptop on-line. If the timers need to be reset to start counting, this is done by turning the key switch on the PLC from "RUN" to "PROGRAM" and then back to "RUN".)

5.8.15_ RESET the injection total volume to zero from the DTAM screen. The security code for the reset is " 13 ".

5.8.16_ SET the injection flow rate to 0.350 at the DTAM. The security screen code is " 11 ".

5.8.17___ TURN the selector switch on the Jet Pump Motor Starter to ON.

5.8.18_ENSURE all the interlocks for starting the jet pump are made up except for the injection water flow switch by checking the last two rungs of ladder 5 on the laptop computer.

5.8 .19

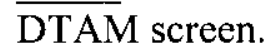

ENSURE the jet pump will not start by attempting to start from the

NOTE: A stopwatch is required for the next step. The stopwatch will remain running until near the end of this section.

PRESS the "start" button on the injection simulator box and ENSURE the red light on the box comes ON and IMMEDIATELY start the stopwatch.

5.8.21_ENSURE the 10-minute timer for the flow switch in ladder 5 on the laptop starts timing. (To expedite this test, the timer can to set to a lower value below 10 minutes.)

5.8.22_ENSURE the jet pump will not start until the timer in the above step times out by attempting to start from the DTAM screen. 


\section{REVISION 0}

5.8.23 ENSURE the jet pump interlocks are made up upon the timing out of the above timer.

5.8.24 OBSERVE that after 4 minutes after the "start" button on the injection simulator box is pressed, the injection total on the DTAM screen is a value greater than zero.

CAUTION: The jet pump starting control has been revised to perform a bump start the first time the pump starts upon the making up of the flow switch interlock. The bump start consists of three cycles of a one-second run time followed by a 10-second stop time. Upon the completion of the three bump cycles, the pump will automatically go to the normal run mode. START the jet pump from the DTAM.

5.8 .26 ENSURE the following occur:

"BUMP START" on the DTAM start screen shows ON. "NORMAL START" on the DTAM start screen shows OFF. ENSURE the pump runs for approximately 1 second. time. ENSURE the pump red $O N$ light comes $O N$ during the 1 -second run stop time.

ENSURE the pump green OFF light comes ON during the 10 -second

ENSURE the pump stops for approximately 10 seconds. ENSURE the horn does not sound during the 10-second stop time. ENSURE that the shutdown output in ladder 5, N20:32/2 does not activate during the 10 -second stop time during the bump sequence.

ENSURE the bump sequence goes through three complete cycles.

ENSURE the jet pump goes to normal starting upon the completion of the three bump cycles by observing the following:

The pump RED run light remains ON continuously.

The pump GREEN off light remains OFF.

The "NORMAL START" on the DTAM screen shows ON. The "BUMP START" on the DTAM screen shows OFF. 


\section{RPP-6707 \\ REVISION 0}

NOTE: The following several steps will be checking the pump interlocks. The pump will be started and stopped during this time. No bump starting should be experience until the flow switch interlock is checked. If the interlock testing is interrupted and the pump shutdown for an extended period, then a bump sequence will be repeated prior to continuing the interlock check. The interlock circuit and pump trouble circuits are also tied into the bump control and will be checked after the interlock check during pump normal run. If the injection simulator box and PLC are turned OFF, the stopwatch is to be stopped and time recorded in the ACCEPTANCE TEST LOG. The stopwatch will be restarted when the injection box is turned back ON.

\section{JUMPER FLUSH PRESSURE SIGNAL TO PLC}

5.8.28_ENSURE a current source is connected to points JFPT+ and JFPT- in the Intrinsic Safe panel intrinsic terminal board and is set to approximately $6 \mathrm{~mA}$.

5.8.29_ENSURE the green light on the Instrument Enclosure and on the Jet Pump motor starter are ON.

5.8.30 APPLY software forces as necessary to allow the jet pump to start. (Engineering will apply the forces from the laptop computer connected to the PLC.)

5.8.31_START the jet pump from the DTAM and OBSERVE that the red lights at the Instrument Enclosure and motor starter come $\mathrm{ON}$ and the green lights at both locations turn OFF.

5.8.32 SLOWLY INCREASE the JFPT current source output to approximately $12.5 \mathrm{~mA}$ or until the pump shuts down after a 3 second delay. OBSERVE the following: (Acknowledge the alarms as necessary to observe all the alarms.)

The jet pump shuts down.

Red lights at the Instrument Enclosure and Motor Starter turn OFF Green lights at the Instrument Enclosure and Motor Starter come ON Horn sounds Strobe light flashes Record current reading on current source. $\mathrm{mA}$ Alarm 3 occurs, "Flush Pressure HI". Alarm 12 occurs, "JET PUMP SHUTDOWN". Blue light at the Instrument Enclosure is $\mathrm{ON}$. The "PS2 FL PR" is approximately 15 psi. psi Ensure addresses $\mathrm{N} 20: 32 / 2$ and N20:32/5 are actuated as observed on the laptop. ENSURE the pump does not start from the DTAM. 

DECREASE the current source to approximately $4 \mathrm{~mA}$.

5.8 .35 ENSURE the "Flush Press" alarm at the DTAM returns to "norm".

5.8 .36 ENSURE the blue light at the Instrument Enclosure turns OFF.

5.8 .37 ENSURE address N20:32/5 clears as observed on the laptop.

5.8 .38 START the jet pump from the DTAM.

5.8 .39 ENSURE address N20:32/2 clears as observed on the laptop.

NOTE: The following "starts" and "stops" assume the red and green lights, horn and strobe light respond appropriately and will not be recorded in the ATP steps.

5.8.40___ DECREASE the current source to zero.

5.8.41___ENSURE the jet pump shuts down.

5.8.42___ENSURE alarm 16, "JFPT SIGNAL LOSS ALARM" occurs.

5.8.43_ ACKNOWLEDGE the alarm.

5.8.44___ ENSURE address N20:32/8 actuates as observed on the laptop.

5.8.45___ INCREASE the current source to approximately $6 \mathrm{~mA}$.

5.8.46___ENSURE the "JFPT SIGNAL" alarm returns to "norm" on the DTAM.

5.8.47_ENSURE address N20:32/8 clears as observed on the laptop.

\section{TRANSFER PRESSURE INTERLOCK INPUT}

5.8.48_ENSURE a current source is connected to points PXPT + and PXPT- in the Intrinsic Safe panel intrinsic terminal board and is set to approximately $6 \mathrm{~mA}$.

ENSURE the laptop computer is connected to the PLC and is "on-line".

5.8.50_ ENSURE the green light on the Instrument Enclosure and on the Jet Pump motor starter are ON. START the jet pump from the DTAM. 


\section{RPP-6707 \\ REVISION 0}

5.8 .52 DECREASE the PXPT current source to approximately $4.8 \mathrm{~mA}$ or until Timer 4.1 on the ladder logic of the PLC (rung 0 of ladder 5) starts timing.

5.8.53 EN__ ENSURE the amber light on the Instrument Enclosure turns ON immediately after the timer starts.

5.8.54 ENSURE after 30 seconds, the following occurs: (Acknowledge alarms as necessary to view all the alarms.)

The jet pump shuts down.

"XFR Pressure LOW" (alarm 1) occurs at the DTAM.

"JET PUMP SHUTDOWN" (alarm12) occurs at the DTAM.

Record the "XFR PRESS" from the DTAM screen. PSI (approximately 15PSI)

INCREASE the current source to approximately $6 \mathrm{~mA}$.

5.8.56_ENSURE the "XFR Pressure" alarm is "norm" on the DTAM and the amber light is OFF on the Instrument Enclosure.

5.8.57_ START the pump from the DTAM.

5.8.58 INCREASE the PXPT current source to approximately $11.5 \mathrm{~mA}$ or until Timer 4.2 on rung 2 of ladder 5 starts timing as observed on the laptop computer.

5.8.59_ENSURE after a 3 second delay, the following occurs: (Acknowledge alarms as necessary to view all the alarms.)

The jet pump shuts down.

"XFR Pressure HIGH" (alarm 2) occurs at the DTAM.

"JET PUMP SHUTDOWN" (alarm12) occurs at the DTAM.

Record the "XFR PRESS" from the DTAM screen. PSI (approximately 140PSI)

5.8 .60 DECREASE the current source to approximately $6 \mathrm{~mA}$.

5.8.61_ENSURE the "XFR Pressure" alarm indicates "norm" on the DTAM.

\section{JR-1 VALVE POSITION INPUT (LS-1 AND LS-2)}

5.8.62_ENSURE the amber lights are ON and the red lights are Off for LS-1 and LS-2 at the Pepperl-Fuchs modules in the IS panel. START the pump from the DTAM. 


\section{RPP-6707 \\ REVISION 0}

5.8.64___ REMOVE the metal from the front face of LS-1.

5.8.65_ENSURE the following occurs immediately: (Acknowledge alarms as necessary to view all the alarms.)

The jet pump shuts down.

"JR-1 Position NON-PROCESS" (alarm 5) occurs at the DTAM.

"JET PUMP SHUTDOWN" (alarm12) occurs at the DTAM.

Address N20:32/0 on ladder 5 is actuated as observed on the laptop. ENSURE the amber light on the Pepperl-Fuchs is OFF for light set 1.

5.8 .66

REMOVE the metal form the front face of LS-2.

5.8.67_ENSURE the "JR-1" still indicates "NON-PROCESS" at the DTAM.

5.8.68___ ENSURE the amber light on the Pepperl-Fuchs is OFF for light set 2.

5.8.69_ENSURE address N20:32/1 is actuated and address N20:32/0 is clear on ladder 5 as observed on the laptop.

5.8.70_ REPLACE the metal in front of LS-1 and LS-2.

5.8.71 ENSURE the "JR-1" indicates "norm" on the DTAM and addresses $\mathrm{N} 20: 32 / 0$ and $\mathrm{N} 20: 32 / 1$ are clear on ladder 5 as observed on the laptop.

5.8.72 ENSURE the amber lights on the Pepperl-Fuchs are ON for both LS-1 and LS-2.

\section{DILUTION LOW FLOW}

5.8.73_ START the pump from the DTAM.

5.8.74___ OPEN the dilution switch at TB4 in the Instrument Enclosure.

5.8.75_ENSURE the following occurs after a 5-minute delay: (Acknowledge alarms as necessary to view the alarms.)

The jet pump shuts down.

"JET PUMP SHUTDOWN"'(alarm 12) occurs at the DTAM.

"DILUTION TANK NO FLOW" (alarm 36) occurs at the DTAM.

5.8 .76

CLOSE the dilution switch. 


\section{RPP-6707 \\ REVISION 0}

5.8.77_ENSURE the "Dilution tk" alarm indicates "norm" on the DTAM. (The "norm" returns once the alarm is acknowledge since the MR-1 contact is in series with alarm and opens when the pump shut downs thus clearing the alarm.)

\section{MOTOR WINDING HIGH TEMPERATURE} START the pump from the DTAM.

5.8 .79 INCREASE the temperature on the temperature simulator to approximately 390 degrees $F$ or greater until the following occurs:

The jet pump shuts down.

"JET PUMP SHUTDOWN" (alarm12) occurs at the DTAM. DTAM.

"Motor Winding High Temp Shutdown" (alarm 14) occurs at the

5.8.80 DECREASE the temperature simulator to approximately 370 degrees $\mathrm{F}$ or lower until alarm "MTR TEMP" indicates "norm" at the DTAM.

\section{POWER MONITOR INTERLOCK}

5.8.81_START the pump from the DTAM.

5.8.82 OPEN the power monitor switch and observe the following.

"JET PUMP SHUTDOWN" (alarm 12) occurs at the DTAM.

"POWER MONITOR HI/LO SHUTDOWN" (alarm 38) occurs at the DTAM.

5.8.83 CLOSE the power monitor switch and ensure the "PWR MONITOR" returns to "norm" on the DTAM.

\section{BY-105 LEAK DETECTION INTERLOCK}

5.8 .84 START the pump from the DTAM.

5.8.85_OPEN the "BY105" switch and observe the following. "JET PUMP SHUTDOWN" (alarm 12) occurs at the DTAM. "BY-105 LEAK OR TROUBLE" (alarm 17) occurs at the DTAM.

5.8.86 CLOSE the "BY105" switch and ensure the "BY105 LK/TRB" returns to "norm" on the DTAM. 


\section{BX-DCRT ALARM INTERLOCK}

5.8 .87 START the pump from the DTAM.

5.8 .88 OPEN the "BX-DCRT" switch and observe the following.

"JET PUMP SHUTDOWN" (alarm 12) occurs at the DTAM. "244-BX-DCRT ALARMS" (alarm 23) occurs at the DTAM.

5.8.89_CLOSE the "BX-DCRT" switch and ensure the "BX DCRT ALARMS" returns to "norm" on the DTAM.

\section{JET PUMP TROUBLE INTERLOCK}

5.8.90_ START the pump from the DTAM.

5.8.91_ TURN the selector switch on the jet pump motor starter to OFF.

5.8.92___ ENSURE the following occurs:

Pump shuts down Alarm 4, "Jet Pump Trouble" occurs.

Alarm 12, "Jet Pump Shutdown" occurs.

5.8 .93

TURN the selector switch on the jet pump motor starter to ON.

5.8 .94 ENSURE the pump does not automatically restart.

\section{LEAK DETECTION INTERLOCK}

5.8.95_ENSURE there is a water supply and bucket available to actuate the leak detector probes.

5.8.96_ START the pump from the DTAM.

5.8.97__ PLACE the primary leak detector probe in a bucket of water.

5.8.98__ENSURE the following occurs after a 3-second delay: (Acknowledge alarms as necessary to view the alarms.)

The jet pump shuts down. "PUMP PIT LEAK" (alarm 6) occurs at the DTAM. "JET PUMP SHUTDOWN" (alarm12) occurs at the DTAM. The red light for the "Primary" leak detector is ON at the Instr. Encl. Ensure address N20:32/3 in ladder 5 actuates as observed on the laptop. 
5.8.99_REMOVE the leak detector probe from the bucket and allow the water to drain off.

5.8.100___ENSURE the "Pump Pit" leak alarm returns to "norm".

5.8.101___ ENSURE the red light for the "Primary" leak detector is OFF.

5.8.102___ENSURE address N20:32/3 clears as observed on the laptop.

5.8.103_ START the pump from the DTAM.

5.8.104_DISCONNECT one of the "SD" wires going to the primary leak detector probe.

5.8.105_ENSURE the following occurs after a 3-second delay: (Acknowledge alarms as necessary to view the alarms.)

The jet pump shuts down.

"PUMP PIT LEAK TROUBLE" (alarm 7) occurs at the DTAM.

"JET PUMP SHUTDOWN" (alarm12) occurs at the DTAM.

The red light for the "Primary" leak detector at the Instrument Enclosure is ON.

Ensure address N20:32/3 actuates as observed on the laptop.

5.8.106_ RECONNECT the "SD" wire.

5.8.107_ENSURE the "Pump Pit" trouble alarm indicates "norm" on the DTAM.

5.8.108___ ENSURE the red light for the "Primary" leak detector is OFF.

5.8.109___ ENSURE address N20:32/3 clears as observed on the laptop.

5.8.110__ START the pump from the DTAM.

5.8.111___ PLACE the leak detector 1 probe in a bucket of water.

5.8.112_ENSURE the following occurs after a 3-second delay: (Acknowledge alarms as necessary to view the alarms.)

The jet pump shuts down.

"JET PUMP SHUTDOWN" (alarm12) occurs at the DTAM.

"LEAK DETECTOR NO 1 LEAK DETECTED" (alarm 18) occurs at the DTAM.

The red light for "Leak Detector 1" at the Instrument Enclosure is ON. Ensure address N20:32/4 actuates in ladder 5 as observed on the laptop. 
5.8.113_ REMOVE the leak detector probe from the bucket and allow the water to drain off.

5.8.114_EN_ENSURE the "Leak Det 1" alarm returns to "norm".

5.8.115___ENSURE the red light for "Leak Detector 1" is OFF.

5.8.116___ENSURE address N20:32/4 clears as observed on the laptop.

5.8.117___ START the pump from the DTAM.

5.8.118___ DISCONNECT one of the "SD" wires going to the leak detector 1 probe.

5.8.119_ENSURE the following occurs after a 3-second delay: (Acknowledge alarms as necessary to view the alarms.)

The jet pump shuts down.

"JET PUMP SHUTDOWN" (alarm12) occurs at the DTAM.

"LEAK DETECTOR NO 1 TROUBLE" (alarm 19) occurs at the $\overline{\text { DTAM. }}$

The red light for "Leak Detector 1" at the Instrument Enclosure is ON. Ensure address N20:32/4 actuates as observed by the laptop.

5.8 .120 RECONNECT the "SD" wire. ENSURE the "Leak Det 1 ck" alarm indicates "norm" on the DTAM. ENSURE the red light for "Leak Detector 1" is OFF. ENSURE address N20:32/4 clears as observed on the laptop.

\section{INJECTION FLOW SWITCH}

5.8 .124 START the pump from the DTAM.

5.8.125_PRESS the "stop" button on the injection simulator box and IMMEDIATELY STOP the stopwatch and OBSERVE that the RED light on the injection simulator box turns OFF. Record the time on the stopwatch. minutes 


\section{RPP-6707 \\ REVISION 0}

5.8 .126 ENSURE the following occurs:

"JET PUMP SHUTDOWN" (alarm12) occurs at the DTAM.

DTAM.

"PUMP INJECTION WATER LOW FLOW" (alarm 39) occurs at the

5.8 .127 RECORD the injection total volume from the DTAM screen. Gallons

5.8.128_CALCULATE the total gallons from the recorded stopwatch time and flow rate. Total gallons $=$ minutes $\mathrm{X}$ gpm flow rate (step 5.9.14)

5.8.129 COMPARE the totals from steps 5.9.116 and 5.9.117. Values to be within $+/-3$ gallons.

5.8 .130 PRESS the "start" on the injection simulator box and ENSURE the "red" light comes ON.

5.8.131 ENSURE the "INJECTION WTR" returns to "norm" after the 10minute timer times out in ladder 5 on the laptop. (If the timer has been set lower, then the return to "norm" will be when the timer times out at the new time.)

\section{PUMP START/STOP FROM DTAM} START the pump from the DTAM.

5.8.133_ ENSURE the pump starts in the bump mode.

5.8.134_ALL_ ALW the bump cycles to complete and the pump go to the normal run mode.

5.8.135_ STOP the pump from the DTAM and observed that the following occurs:

"JET PUMP SHUTDOWN" (alarm12) occurs at the DTAM. ENSURE the 30-minute timer in ladder 7 observed on the laptop starts timing. (To expedite the testing, the time can be decreased on the timer.)

5.8.136___ UPON time-out of the 30-minute timer, ENSURE the injection simulator red light turns $\mathrm{OFF}$ 
NOTE: The following steps will check the bump start control logic. The pump will be put through a few bump sequences (some only partial sequences) to ensure the logic meets the same safety requirements as in the normal run mode such as interlock shutdowns. Not all interlocks will be checked since the same interlock contact is used in both the bump and normal run modes.

5.8 .137 PRESS the "start" on the injection simulator box and ENSURE the "red" light comes ON.

5.8.138 ENSURE the "INJECTION WTR" returns to "norm" after the 10minute timer times out in ladder 5 on the laptop. (If the timer has been set lower, then the return to "norm" will be when the timer times out at the new time.)

5.8.139_START the jet pump from the DTAM after the flow switch interlock is made up.

5.8.140___ ENSURE the pump starts in the BUMP start mode.

5.8.141_INCREASE the motor winding temperature simulator to 390 degrees $\mathrm{F}$ or higher during the first bump cycle until a shutdown occurs and observe the following.

ENSURE the bump start on the DTAM screen shows OFF ENSURE the horn sounds ENSURE the strobe light flashes ENSURE alarm 12 occurs ENSURE alarm 14 occurs ENSURE address N20:32/2 in ladder 5 is actuated. ENSURE the counter in ladder 7 resets to zero.

5.8.142_ DECREASE the motor winding temperature simulator to 370 degrees or lower until the alarm clears.

5.8.143___ ENSURE the pump does not automatically restart when the interlock is cleared.

5.8.144___ START the pump from the DTAM.

5.8.145___ ENSURE the pump starts in the BUMP start mode.

5.8.146_ TURN the pump selector-switch to OFF at the motor starter during the second bump cycle. 


\section{RPP-6707 \\ REVISION 0}

5.8.147___ENSURE the following occurs (Several seconds may elapse depending upon where in the bump cycle the switch is turned OFF).

ENSURE the bump start on the DTAM screen shows OFF

ENSURE the horn sounds

ENSURE the strobe light flashes

ENSURE alarm 4 occurs

ENSURE alarm 12 occurs

ENSURE address N20:32/2 in ladder 5 is actuated.

ENSURE the counter in ladder 7 resets to zero.

5.8 .148

TURN the selector switch to ON.

5.8.149___ENSURE the pump does not automatically start.

5.8 .150 START the pump from the DTAM.

5.8.151___ ENSURE the pump starts in the bump mode.

5.8.152_ STOP the pump from the DTAM during the third bump cycle and ENSURE the following occurs.

ENSURE the bump start on the DTAM screen shows OFF

ENSURE the horn sounds

ENSURE the strobe light flashes

ENSURE alarm 12 occurs

ENSURE address N20:32/2 in ladder 5 is actuated.

ENSURE the counter in ladder 7 resets to zero.

5.8 .153

START the pump from the DTAM.

5.8 .154

ENSURE the pump starts in the bump mode.

5.8.155_ PRESS the "stop" button on the injection simulator box and OBSERVE that the RED light on the injection simulator box turns OFF.

5.8.156___ ENSURE the following occurs:

"JET PUMP SHUTDOWN" (alarm12) occurs at the DTAM. DTAM.

"PUMP INJECTION WATER LOW FLOW" (alarm 39) occurs at the 


\section{HOUR-METER CHECK}

5.8.157__ RECORD the hour-meter reading.

5.8.158_ VERIFY by comparing the readings in steps 5.9.10 and 5.9.122 that the hour-meter is recording time.

\section{INTERLOCK TEST SHUTDOWN}

5.8.159_ REMOVE the software forces and disconnect the laptop computer from the PLC. This includes resetting any timers back to the original settings.

5.8.160_TURN OFF breakers 2, 3,5, and 6 in the distribution panel.

5.8.161_ DISCONNECT the current sources from the PXPT and JFPT termination points.

5.8.162_DISCONNECT the test switches from the BY105, BX-DCRT, power monitor, injection simulator box, and Dilution termination points.

5.8.163_ DISCONNECT the proximity switches from the Intrinsic Safe panel.

5.8.164__ DISCONNECT the temperature simulator from the Intrinsic Safe panel.

5.8.165_DISCONNECT the leak detector probes from the Instrument Enclosure.

5.8.166_ TURN ON breakers $2,3,5$, and 6 at the distribution panel.

5.8.167Engineer to ENSURE section 5.9 is completed and sign below.

Engineer Signature

Date

5.8.168Quality Assurance Inspector to VERIFY that section 5.9 is completed and sign below.

Quality Assurance Inspector Signature

Date 


\subsection{HEATERS, AIR CONDITIONER AND LIGHTS}

5.9.1 TURN the heater ON in the air compressor cabinet. Set the thermostat high enough to allow the unit to operate.

5.9.2 RESET the thermostat to approximately 40 degrees $F$ to allow the heat to turn OFF. Then unplug the heater.

5.9.3 TURN the fan thermostat switch to allow the fan in the air compressor cabinet to run.

5.9.4_ RESET the fan switch to approximately 90 degrees $F$ to allow the fan to turn OFF.

5.9.5_ TURN the heater ON in the WFIE cabinet. Set the thermostat high enough to allow the unit to operate.

5.9.6_ RESET the thermostat to approximately 40 degrees $F$ to allow the heat to turn OFF. Then unplug the heater.

5.9.7_ TURN the heater ON in the Water cabinet. Set the thermostat high enough to allow the unit to operate.

5.9.8 RESET the thermostat to near the "LO" setting to allow the heat to turn OFF. Then unplug the heater.

5.9.9 TURN the heater ON in the Instrument Enclosure. Set the thermostat high enough to allow the unit to operate.

5.9.10_ RESET the thermostat to approximately 40 degrees $F$ to allow the heat to turn OFF. Then unplug the heater.

5.9.11_ TURN ON the air conditioner in the Instrument Enclosure. If necessary, remove the front grill on the unit and adjust the temperature setting to get the unit to operate.

5.9.12_RESET the temperature setting on the air conditioner to between 90 to 95 degrees F. Remove the grill and filter on the front of the air conditioner for access to the adjustment. Then unplug the air conditioner.

5.9.13___ENSURE the light in the WFIE cabinet operates.

5.9.14_ENSURE the light in the Instrument Enclosure operates. 


\section{RPP-6707 \\ REVISION 0}

5.9.15 Engineer to ENSURE that section 5.10 is completed and sign below.

Engineer Signature Date

5.9.16 Quality Assurance Inspector to VERIFY that section 5.10 is completed and sign below.

Quality Assurance Inspector Signature

Date 


\subsection{SKID PREPARATION FOR SHIPPING}

5.10.1. Ensure the following PIC skid circuit disconnects, breakers and fuses are OPEN or OFF.

DS-6002U
DS-6003U
DS-6004U
DS-6005U

The breakers below are located in the distribution panel DP-6001U:

\begin{tabular}{c} 
Breaker "MAIN" \\
Breaker 1 \\
Breaker 3 \\
Breaker 5 \\
Breaker 7 \\
Breaker 9 \\
\hline Breaker 11 \\
\hline Breaker 13
\end{tabular}

Breaker 2 Breaker 4 Breaker 6 Breaker 8 Breaker 10 Breaker 12 Breaker 14

5.10.2.___ Disconnect the power plug from the 480vac power source.

5.10.3. ENSURE the power plug on the power cable is a Crouse-Hinds model APJ3475.

5.10.4. DRAIN the water tank in the Water Cabinet. If the tank is drained with pressure on the tank, then use at least a $3 / 4$ " or 1" diameter hose. If a small hose is used, then bleed pressure off the tank by closing V-6027U and opening V$6037 \mathrm{U}$ prior to opening drain valve $\mathrm{V}-6030 \mathrm{U}$.

5.10.5. __ Bleed the air pressure off the air system by OPENING the following valves:

\begin{tabular}{r}
$\mathrm{V}-6043 \mathrm{U}$ \\
\hline $\mathrm{V}-6046 \mathrm{U}$ \\
$\mathrm{V}-6047 \mathrm{U}$ \\
$\mathrm{V}-6037 \mathrm{U}$
\end{tabular}

NOTE: After the air system has bled down, proceed with the following valve positioning. 


\section{RPP-6707 \\ REVISION 0}

5.10.6. Ensure the following PIC skid valves in the WFIE cabinet are OPEN.

$\begin{array}{r}\text { V-6035U (EQUALIZING) } \\ \hline \text { V-6036U (EQUALIZING) }\end{array}$

5.10.7.___ Ensure the following valves are CLOSED.

Air Compressor

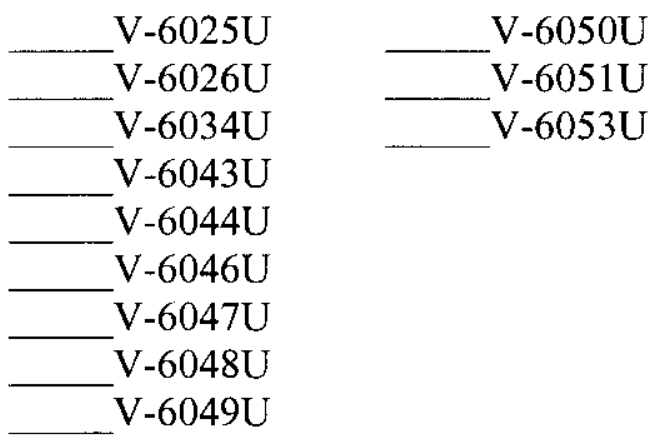

WFIE Cabinet

$\mathrm{V}-6001 \mathrm{U}$
$\mathrm{V}-6002 \mathrm{U}$
$\mathrm{V}-6003 \mathrm{U}$
$\mathrm{V}-6004 \mathrm{U}$
$\mathrm{V}-6005 \mathrm{U}$
$\mathrm{V}-6006 \mathrm{U}$
$\mathrm{V}-6007 \mathrm{U}$
$\mathrm{V}-6008 \mathrm{U}$
$\mathrm{V}-6011 \mathrm{U}$

V-6012U $\mathrm{V}-6013 \mathrm{U}$ V-6014U V-6015U V-6016U V-6017U V-6018U V-6019U V-6020U
Water Cabinet

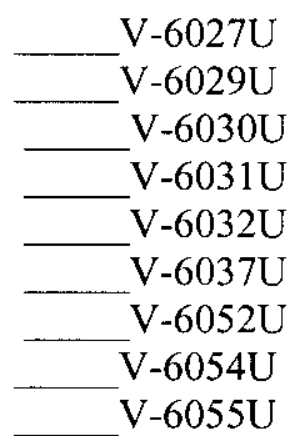

5.10.8 Engineer to ENSURE that section 5.11 is completed and sign below.

Engineer Signature

Date

5.10.9. Quality Assurance Inspector to VERIFY that section 5.11 is completed and sign below.

Quality Assurance Inspector Signature

Date 
RPP-6707

REVISION 0

\subsection{APPENDIX A}

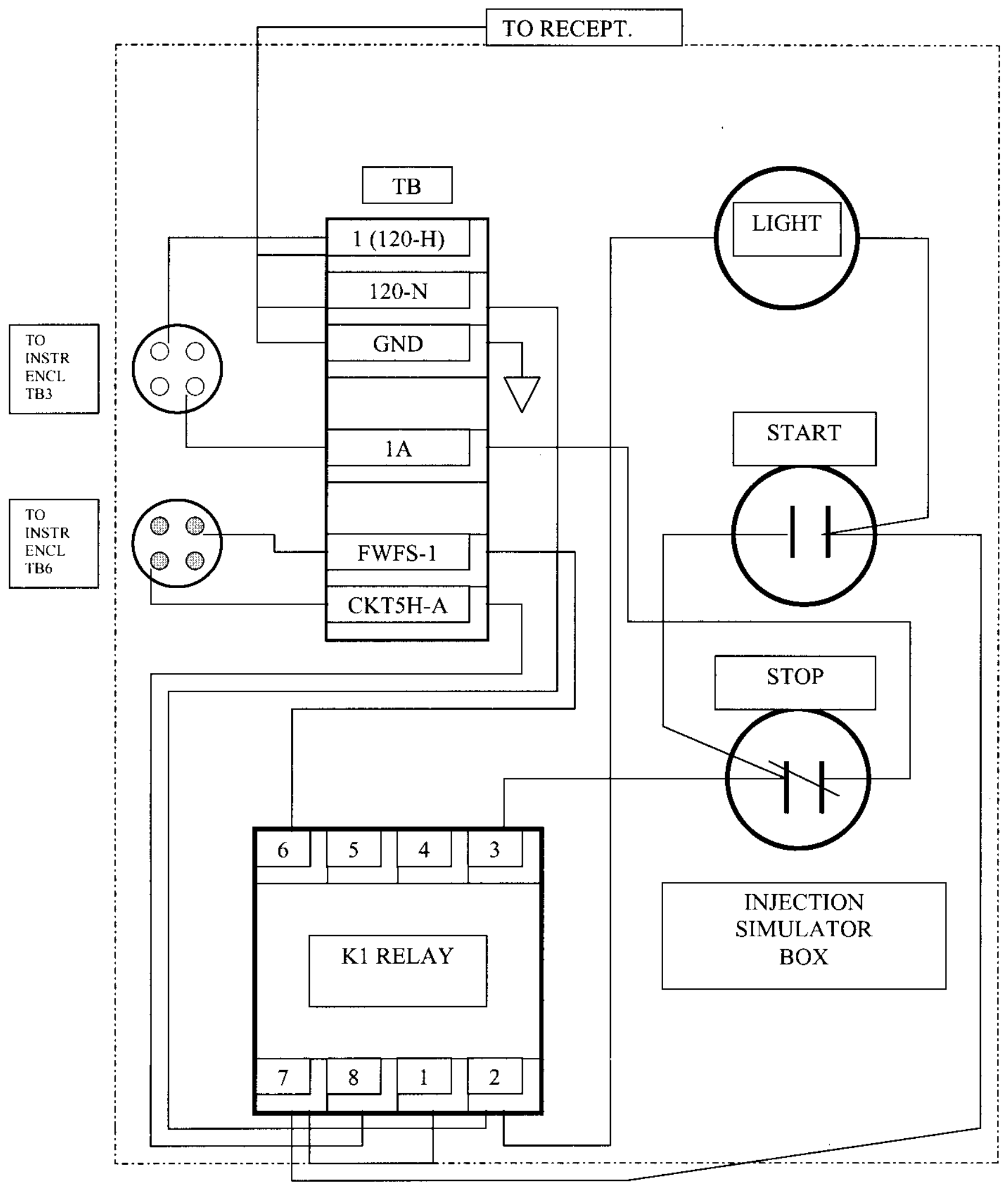




\section{RPP-6707 \\ REVISION 0}

ACCEPTANCE TEST PROCEDURE

This page may be reproduced as necessary

PAGE of

\begin{tabular}{|c|c|c|}
\hline \multicolumn{3}{|c|}{ ACCEPTANCE TEST PROCEDURE LOG } \\
\hline Name & Date & Comment \\
\hline & & \\
\hline & & \\
\hline & & \\
\hline & & \\
\hline & & \\
\hline & & \\
\hline & & \\
\hline & & \\
\hline & & \\
\hline & & \\
\hline & & \\
\hline & & \\
\hline & & \\
\hline & & \\
\hline
\end{tabular}




\section{ACCEPTANCE TEST PROCEDURE EXCEPTION LOG}

This page may be reproduced as necessary

PAGE of

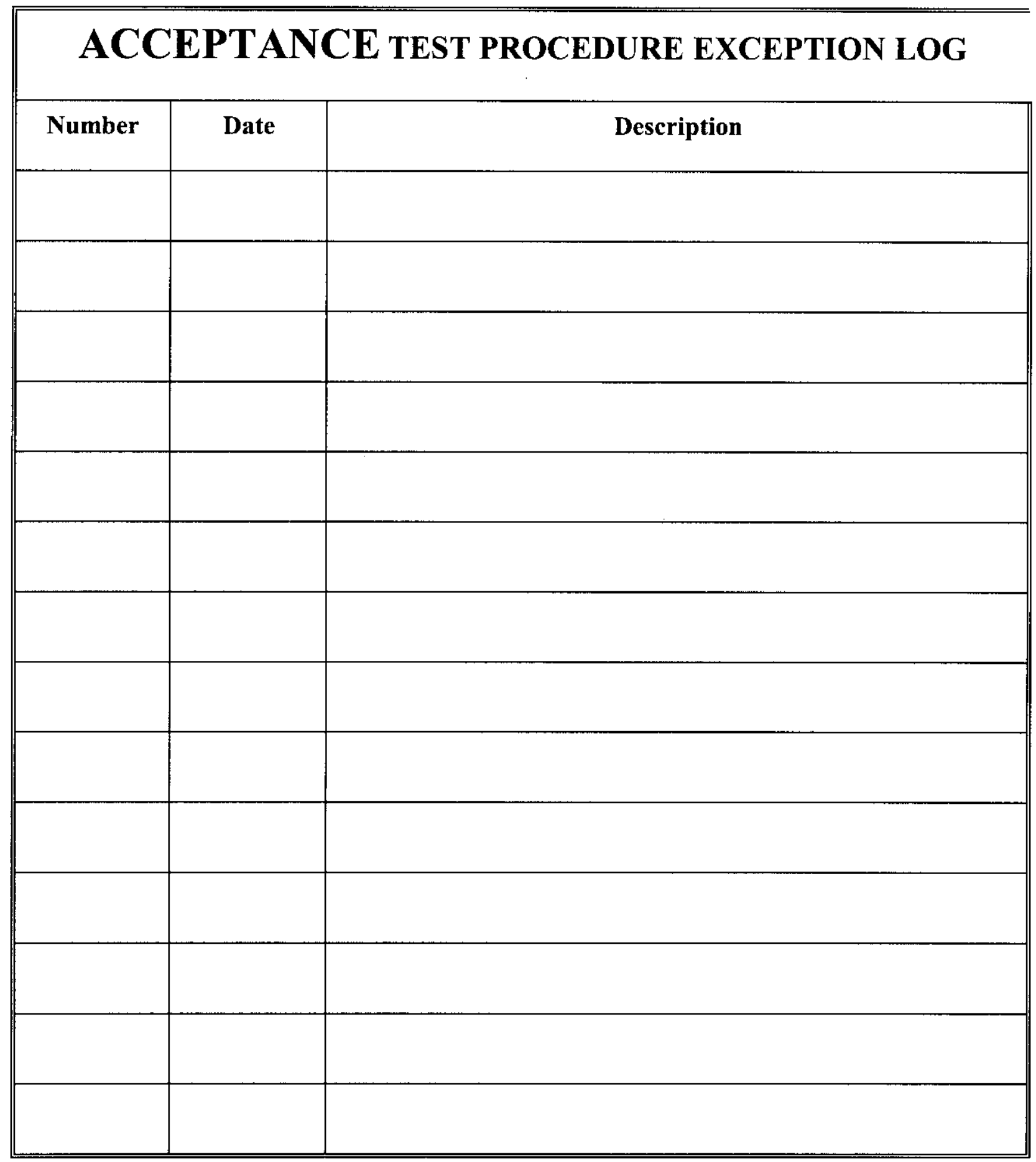




\section{ACCEPTANCE TEST PROCEDURE EXCEPTION RECORD}

This page may be reproduced as necessary.

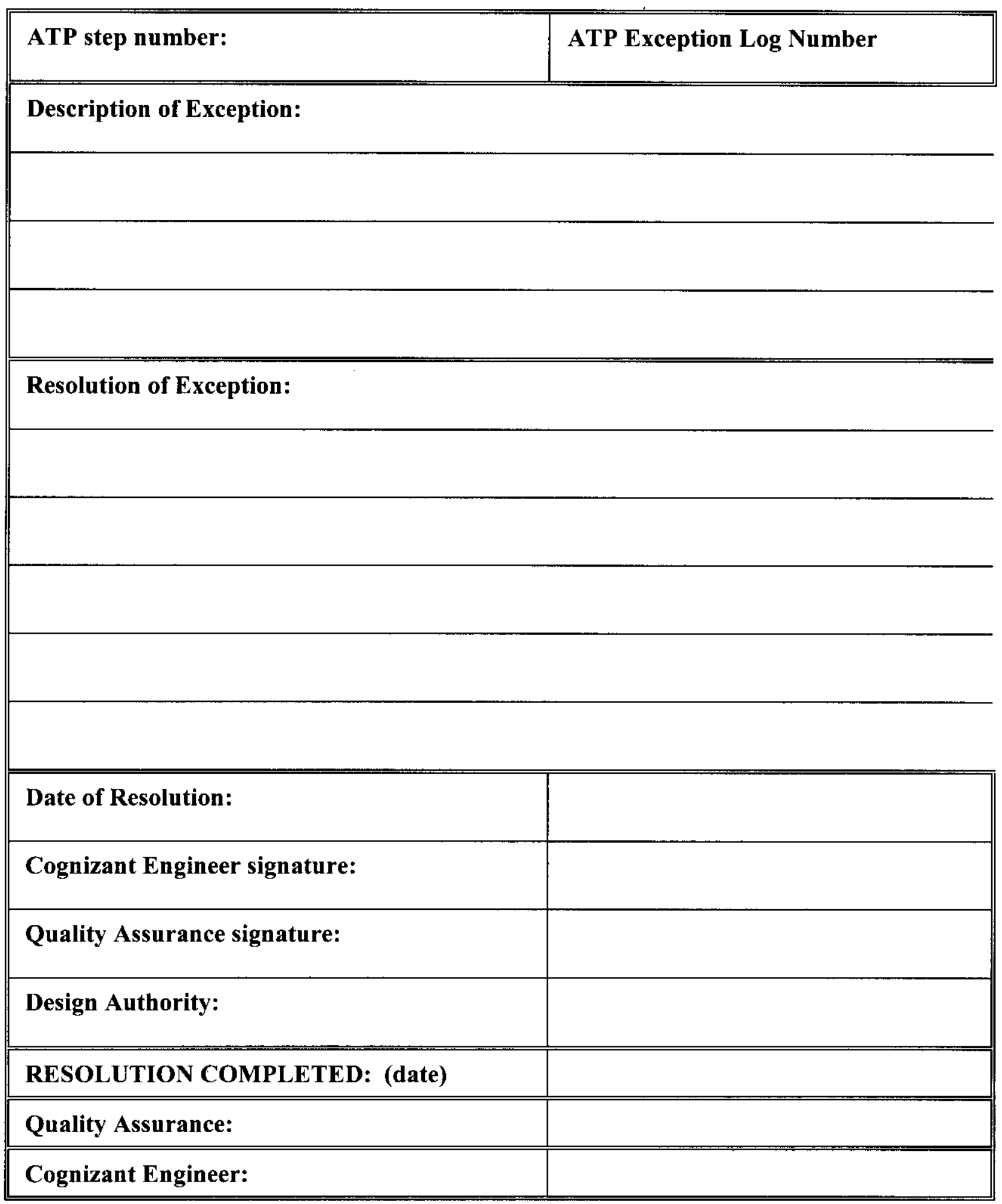




\section{ACCEPTANCE TEST PROCEDURE ACCEPTANCE RECORD}

Section 5.0 of the Acceptance Test Procedure has been completed including completion of all exceptions. The test results are accepted by the undersigned: 


\section{RPP-6707 \\ REVISION 0 \\ PROCEDURE PERFORMER SIGNATURE SHEET}

All personnel who will be performing, initialing and signing the procedure shall enter their printed name, signature and initials below.

\begin{tabular}{|c|c|c|}
\hline PRINT NAME & SIGNATURE & INITIALS \\
\hline & & \\
\hline & & \\
\hline & & \\
\hline & & \\
\hline & & \\
\hline & & \\
\hline & & \\
\hline & & \\
\hline & & \\
\hline & & \\
\hline & & \\
\hline & & \\
\hline & & \\
\hline & & \\
\hline & & \\
\hline & & \\
\hline & & \\
\hline & & \\
\hline & & \\
\hline
\end{tabular}




\section{RPP-6707}

REVISION 0

\section{PRE-JOB BRIEF SIGNATURE PAGE}

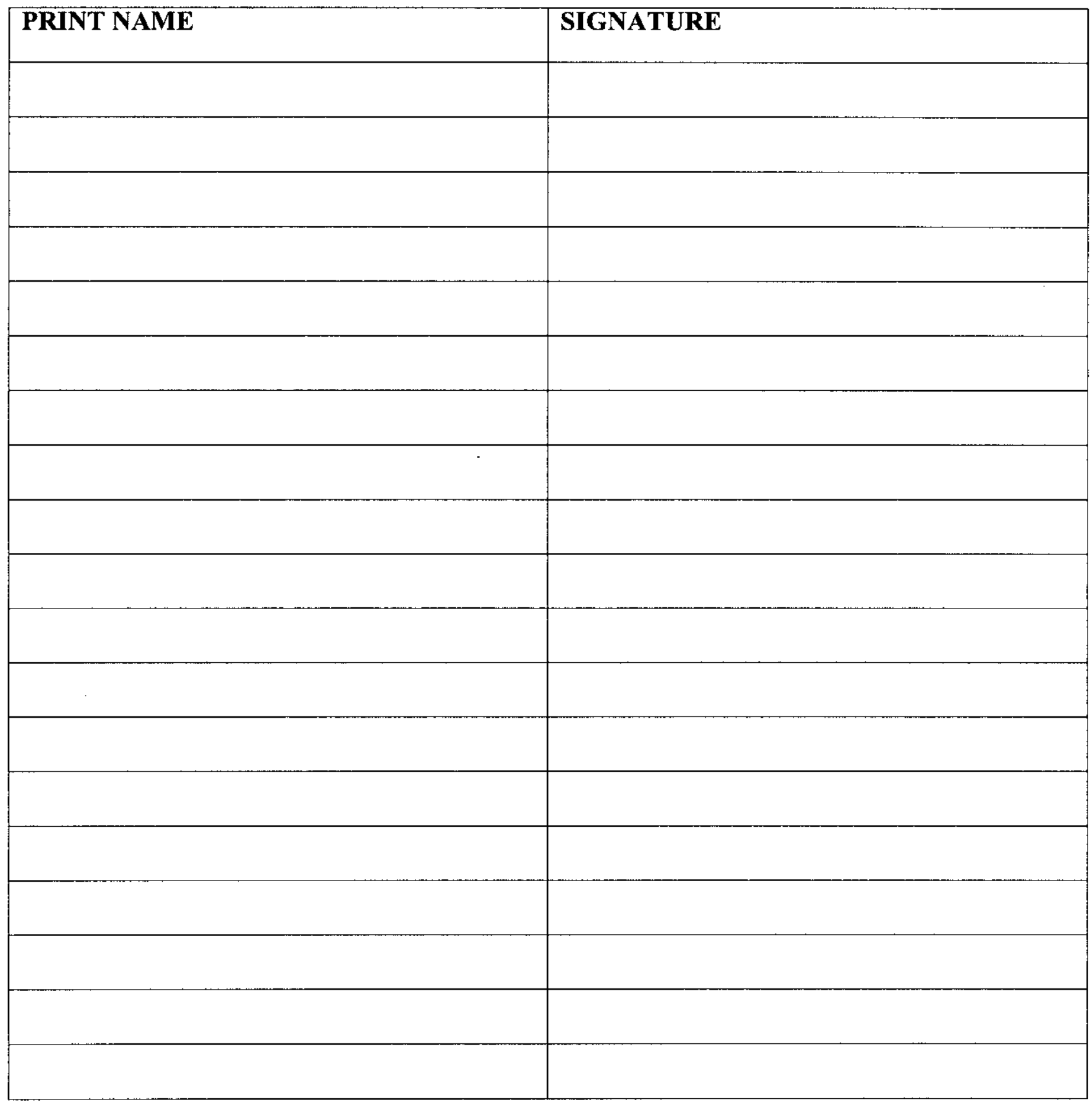

